\title{
光电多孔共价有机材料的研究进展
}

\author{
万刚付宇昂郭佳宁向中华* \\ (有机无机复合材料国家重点实验室 分子能源材料研发中心 北京化工大学 北京 100029)
}

\begin{abstract}
摘要 多孔共价有机材料(Covalent Organic Materials: COMs) 是一类通过共价键将不同几何构型和长度的有机配体组装 成多维度多功能的多孔材料. 在 $\mathrm{COM}$ 材料体系中, 共轭结构赋予它优异的光电性质, 高的比表面积为静电电荷的分离 提供了充裕的界面, 固有的可裁剪孔结构允许离子的传输, 加上高度有序的结构, 为载流子迁移提供了通道, 已经在 半导体和能源转化与存储领域展示出诱人的潜力. 本综述围绕着 COM 材料, 总结其在半导体、能源转化 (光解水、太 阳能电池、燃料电池中的阴极氧化还原反应)、能源存储(锂电、锂硫、超级电容器)中的应用, 并根据当前研究现状, 提 出了设计光电 COM 材料原理. 尽管光电 COM 材料的发展还处于萌芽期, 但它已经展示出不可低估的影响, 在半导体 和新能源领域扮演着越来越重要的作用, 同时也给光电领域带来了新的机遇.
\end{abstract}

关键词＼cjkstart共价有机骨架材料; 共价有机聚合物; 半导体; 光解水; 太阳能电池; 氧还原反应; 锂电池; 超级电容

\section{Photoelectronic Porous Covalent Organic Materials: Research Progress and Perspective}

\author{
Wan, Gang $\quad \mathrm{Fu}, \mathrm{Yu}$ 'ang Guo, Jianing Xiang, Zhonghua* \\ (State Key Laboratory of Organic-Inorganic Composites, Molecular Energy Materials R\&D Center, Beijing University of \\ Chemical Technology, Beijing 100029)
}

\begin{abstract}
Porous covalent organic materials (COM) are a class of multi-dimensional and multi-functional porous materials, which are built via covalent bond of colorful organic building blocks. COM materials possess inherent optimized pore size allowing ion migration, and high specific surface area, providing the possibility of formation of an electrostatic charge-separation layer, a conjugated system resulting in light-harvesting properties and a highly ordered structure, enabling the formation of conductive paths. In this review, we summary the applications on semiconductor, photolysis of water, solar cell, oxygen reduction reaction in fuel cell, lithium-ion/sulfur battery basing on COM materials. Meanwhile, we also propose the design strategy for photoelectronic materials. Although the development of COMs as photoelectronic materials is still in its infancy, COM materials has being attracting ever-increasing attention and open a new window in this field.

Keywords covalent organic frameworks; covalent organic polymers; semiconductor; photolysis of water; solar cell; oxygen reduction reaction; lithium ion battery; supercapacitor
\end{abstract}

\section{1 引言}

近年来, 随着金属有机骨架(metal-organic frameworks: MOF) ${ }^{[1 \sim 10]}$ 的高速发展, 共价有机材料(Covalent organic materials: COMs; 一类类似 MOF 材料的有机多 孔材料)也得到了蓬勃发展 ${ }^{[11]}$. COM 材料和 MOF 材料最 大的区别就是没有金属离子参与配位, 而是通过轻质元 素(主要是元素周期表中第一和第二排主族元素)间的共 价键, 如: $\mathrm{B}-\mathrm{O}, \mathrm{C}-\mathrm{C}, \mathrm{C}-\mathrm{H}, \mathrm{C}-\mathrm{N}$ 等, 连接而成. 如 图 1 所示, 可以和 MOF 材料一样, 通过调节构筑的有机 配体的空间几何构型和长度来定向裁剪孔结构和多孔 性, 也可进一步通过有机配体的修饰, 对材料结构表面
进行功能修饰. 根据结构分类, 可将 COM 材料分成两 大类: (1)晶型结构, 如共价有机骨架材料(Covalent organic frameworks: $\mathrm{COFs})^{[12,13]}$, 嗪基多孔聚合物 (Covalent triazine-based Frameworks: CTFs) ${ }^{[14,15]}$. 这一类 材料是通过化学动力学可逆反应制备出来的; (2)无定型 结构, 比如固有微孔聚合物 (Polymer of intrinsic microporosity: PIMs) ${ }^{[16]}$, 共轭微孔聚合物(Conjugated mi-

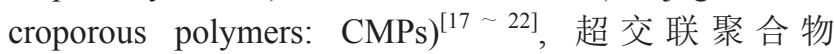
(Hyper-crosslinked Polymers: HCPs) ${ }^{[23,24]}$, 多孔聚合物骨 架材料(porous polymer networks: PPNs) ${ }^{[25,26]}$, 多孔芳香 骨架聚合物(Porous Aromatic Frameworks: PAFs) ${ }^{[27 \sim 30]}$ 和共价有机聚合物 (Covalent organic polymers:

*E-mail: xiangzh@mail.buct.edu.cn; Tel.: 010-64423647.

Received February 11, 2015; published April 13, 2015.

Project supported by the National Hi-tech R\&D Program of China (No. 863 Program, 2012AA101809), the Start-up fund for talent introduction of Beijing University of Chemical Technology (No. buctrc201420), Talent cultivation of State Key Laboratory of Organic-Inorganic Composites (Nos. OIC201403003, OIC201503002) and the Fundamental Research Funds for the Central Universities (ZY1508).

项目受国家高技术研究发展计划(No. 863 计划, 2012AA101809)、北京化工大学人才科研启动(No. buctrc201420)、有机无机复合材料国家重点实验室 人才培育(Nos. OIC201403003, OIC201503002)和中央高校基本科研业务费专项资金(No. ZY1508)资助. 
$\mathrm{COPs})^{[11,31 \sim 36]}$, 这一类材料是通过不可逆反应合成出来 的. 丰富多彩的 COM 材料合成方法在近年来发表综 述 $^{[11 \sim 13,16,19,20,37 \sim 42]}$ 里做了详细的介绍. COM 材料具有优 异的多孔性, 如 PAF-1 ${ }^{[29]}$ 和 PPN-4 ${ }^{[25]}$ 的 BET 比表面积分 别达到 5640 和 $6461 \mathrm{~m}^{2} \cdot \mathrm{g}^{-1}$. 较稳定的共价键赋予了很 多创制的 COM 材料高水热稳定性, 加上有序共轭体系, 使得 COM 在能源气体储存和分离 ${ }^{[11,37,43,44]}$, 催化 剂 $^{[45,46] \text {, 苂光传感 }}{ }^{[47 ~ 49]}$, 半导体光电应用 ${ }^{[50 ~ 54]}$, 新能源 存储与转化 ${ }^{[55 ~ 58]}$, 生物医药等重要领域 ${ }^{[62,63]}$, 具有广泛 的应用前景.

COM 材料中的共轭结构使得它表现出良好的光电 性能, 高的比表面积为静电电荷的分离提供了充裕的界 面, 固有的可裁剪孔结构允许离子的传输, 加上高度有 序的结构, 为载流子迁移提供了通道. 由于高度有序堆 垛模式导致大的静电耦合和电荷非定域化, 使得 COM 材料表现出优异的载流子迁移率, 理论结果预测有望超 过目前最大的寡并苯 $10 \mathrm{~cm}^{2} \cdot \mathrm{V}^{-1} \cdot \mathrm{s}^{-1[64]}$. 近年来, 伴随 着多尺度模型化的高速发展 ${ }^{[3,32]}$, 可以定向设计 $\mathrm{COM}$ 材料, 调控能带和光吸收性能, 来实现定制合成特定功 能光电材料, 因此近年来, $\mathrm{COM}$ 材料被广泛地应用于光 电领域. 本论文将综述近年来 $\mathrm{COM}$ 材料在半导体光电 领域的研究进展, 同时也对 COM 材料在能源转化与存 储领域中的研究进行了总结. 具体分成以下几个小节: 光电 $\mathrm{COM}$ 材料的设计原理, 半导体 $\mathrm{COM}$ 材料(多并苯 类、酞菁、卟啉类、噻吩类等), 能源转化 COM 材料(光 解水、太阳能电池、氧还原反应)和储能 COM 材料(锂 电池、锂硫电池、超级电容器), 最后对该领域做了总结 与展望.

\section{2 光电 $\mathrm{COM}$ 材料的设计原理}

由于有机半导体材料的易加工和化学调控性, 给柔 性和印刷型的电子器件提供了广阔的空间 ${ }^{[65]}$. 然而, 传 统有机半导体小分子电子器件的稳定性和效率比较低, 是该领域面临的重要挑战. 效率偏低的主要原因常常 是, 由于有机半导体材料结构不规则排列或无效或紊乱 的供体一受体界面导致的低载流子迁移率和载流子的复 合引起的. COM 材料的便捷的化学调控和高度有序的 结构, 为突破这一关键科学问题, 提供了平台. 为了获 得较高载流子迁移率, 常常采用有序二维的结构. 这些 完美规则的二维结构可通过图 1 中构筑单元合成, 如: 六边形、四边形或是其组合式结构. 其中, 由于空间结 构的制约, 目前还未见图 1 中 $\mathrm{T}$ 型 $P_{\mathrm{T}}$ 材料的报道 ${ }^{[61]}$.

在目前文献报道中, 除 $\mathrm{COF}-1^{[66]}$ 外, 大部分二维 $\mathrm{COM}$ 材料的结构是以 eclipsed AA 的模式形成的, 而这 一结果也受到理论计算的挑战. Lukose 等 ${ }^{[67,68]}$ 通过紧束 缚密度泛函的计算 (Density Functional based tight-binding: DFTB)方法计算了 COF 材料的结构和能
量. 他们将二维 COF 材料结构的堆垛模式分为图 2 中四 类: eclipsed AA、staggered AB、 serrated 和 inclined 堆垛 模式. 计算发现在完美 AA 堆垛模式中，层与层间结点 极化作用形成的库仑力会让 AA 堆垛模式发生错位或扭 曲等现象, 而在 serrated 和 inclined 堆垛模式的结构具有 比 eclipsed AA 和 staggered AB 堆垛模式的更高的稳定 能量. 在 serrated 和 inclined 堆垛模式, 层与层之间的轨 道互斥作用会变小, 使得结构比简单的 eclipsed AA 模 式更加稳定, 也就是说材料的结构可能会以 serrated 和 inclined 堆垛模式而成. Dichtel 课题组在喼酸酯基的 COF 案例中, 也发现了类似现象 ${ }^{[69]}$. 他们的计算也表明 相邻层会水平错位 $0.17 \sim 0.18 \mathrm{~nm}$, 而不是完美的 $\mathrm{AA}$ 堆 垛模式. 在 Lukose 设计的 COF 体系中, 所有的 COF 材 料均表现出半导体特性, 能带在 $1.7 \sim 4.0 \mathrm{eV}$ 之间. 随着 碳原子的个数增加, 其能带逐渐变小, 也就是构筑 COM 材料的有机配体中并苯类单元越多, 其能带越小. 值得一提的是，尽管单层和多层的态密度非常相似， COM 材料的能带与材堆垛模式和层间距有着非常大的 关系. 从某种意义来讲, 材料的堆垛模式会影响材料的 光电性能. 尽管如此, serrated 和 inclined 堆垛模式的结 构与 eclipsed AA 模式的理论 XRD 谱图常常相似, 很难 通过实验 XRD 谱图判断具体的模式, 因此关于 COM 材 料的堆垛模式还需进一步探究.

Siebbeles 等 ${ }^{[64]}$ 介绍了一种新的计算方法来计算含 有不同分子间距和扭转角度的三亚苯基 COF 材料的离 域电子范围. 他们的计算结果表明片状间的电子耦合主 要取决于层间的距离和扭转角度, 同时也说明了最好的 电子耦合将产生在 eclipsed 堆垛结构中. 因此, 离域的 电子能够沿着堆垛方向, 以依赖于温度的带状机制方式 发生迁移, COFs 材料可被期待具有较高的电子迁移性 能. 不同温度下实验的方法研究了电子的迁移揭示了电 子的传输机理. 理论计算促进实验研究发现了这类材料 的光电子性能，同时也表明在这类材料中能够找到用于 具有潜力的光电材料. 因此总结起来, 为获得良好光电 性质, 最好以 serrated 和 inclined 堆垛模式组装的二维 COM 材料.

在进一步器件制作中, 为获得优异器件效率, 需要 将这些微管规整结构的 COM 材料, 组装或排列成宏观 有序的膜. Medina 等 ${ }^{[70]}$ 通过在不同的多晶表面(如: ITO 玻璃、金表面)原位生长并苯双噻吩基的 COF 膜. 这种 以原位生长膜形成的器件中，载流子迁移比将直接合成 出的 COF 再成膜组装成器件的高效得多, 规则有序的 膜给器件载流子的传输更好的传输通道. Dichtel 课题 组 ${ }^{[71]}$ 和 Liu 课题组 ${ }^{[72]}$, 也在单层石墨烯表面原位生长了 平整规则的二维 COF 膜. Gunasinghe 等借助于离差修正 密度泛函理论研究了石墨烯上的平面 COM 材料的电子 传输性能, 研究了在石墨烯表面定向生长六边形和方形 


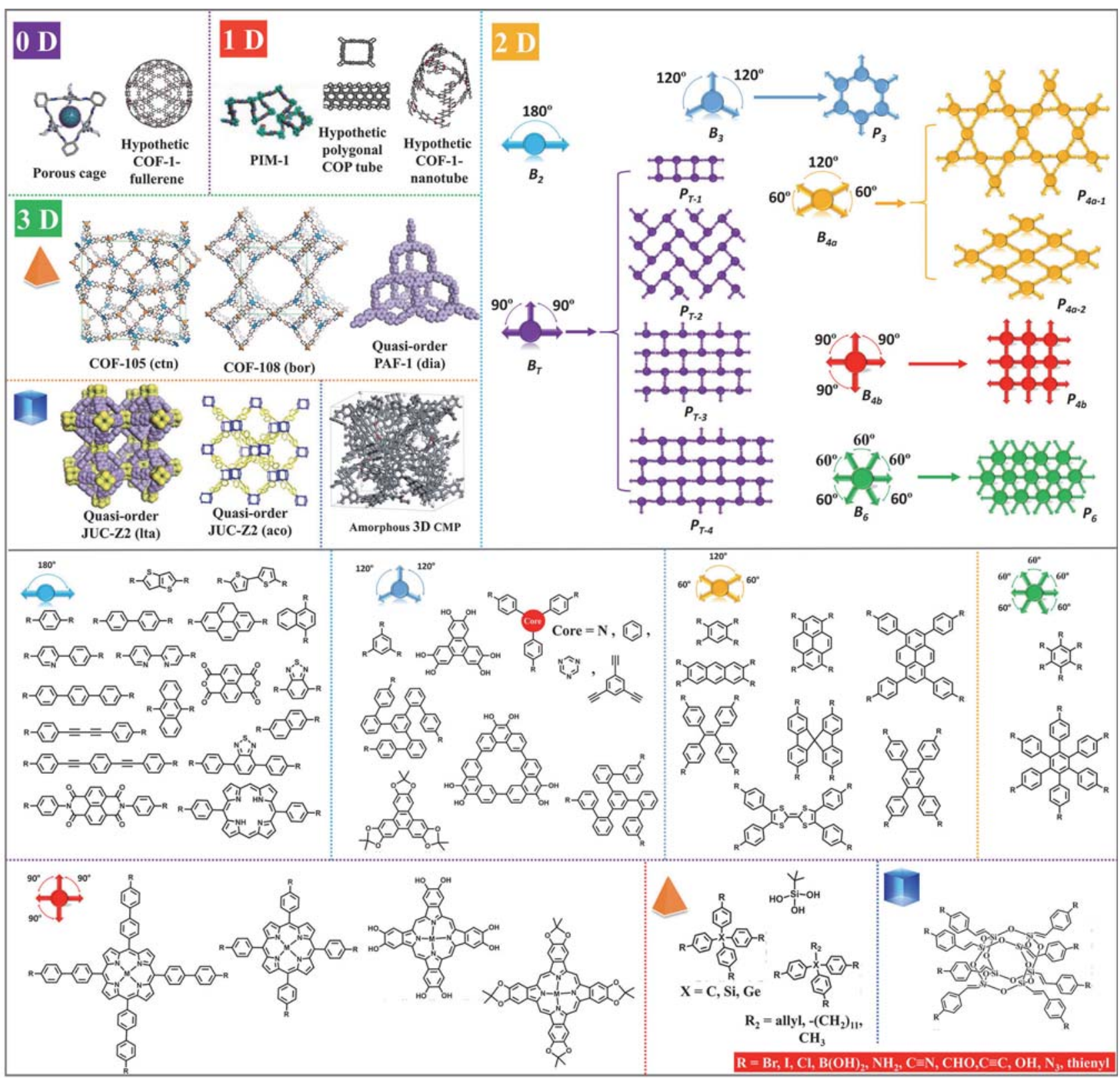

图 1 多维度的共价有机聚合物的结构和常见配体. 除上半部分 COF-1-fullerene/tube ${ }^{[59]}$ 和多边形 COP-tube ${ }^{[60]}$ 是理论构筑外, 其余结构均为实验报 道的结构. 在上半部分的二维结构中, 使用了卡通示意图, 直线型构筑单元可以与其他构筑单元联合延伸材料的结构. B 代表 building block, P 代 表聚合物. 下半部分图中配体中的 $\mathrm{R}$ 基团可为卤素、氨基、氰基、醇羟基、醛基和噻吩基团中任何一种[61]

Figure 1 The multidimensional covalent organic polymers and the related monomers. Except for the hypothetic COF-1-fullerene/tube ${ }^{[59]}$ and polygonal COP-tube ${ }^{[60]}$, all the other materials are experimentally reported. In the upper figure show the main building blocks for $2 \mathrm{D}$ covalent organic polymers, and the strategies for $2 \mathrm{D}$ polymerization. A linear building block $\mathrm{B}_{2}$ can be combined with other building blocks in other shape to extend the structures of $2 \mathrm{D}$ COPs. 'B' refers to the 'building block' and ' $\mathrm{P}$ ' refers to the resulting 'polymer'. In the bottom figure, $\mathrm{R}$ in each of the organic linkers can be one of $\mathrm{Br}$, $\mathrm{B}(\mathrm{OH})_{2}, \mathrm{NH}_{2}, \mathrm{CN}, \mathrm{CHO}, \mathrm{I}, \mathrm{Cl}, \mathrm{OH}, \mathrm{N}_{3}$, alkyl, or thienyl group ${ }^{[61]}$
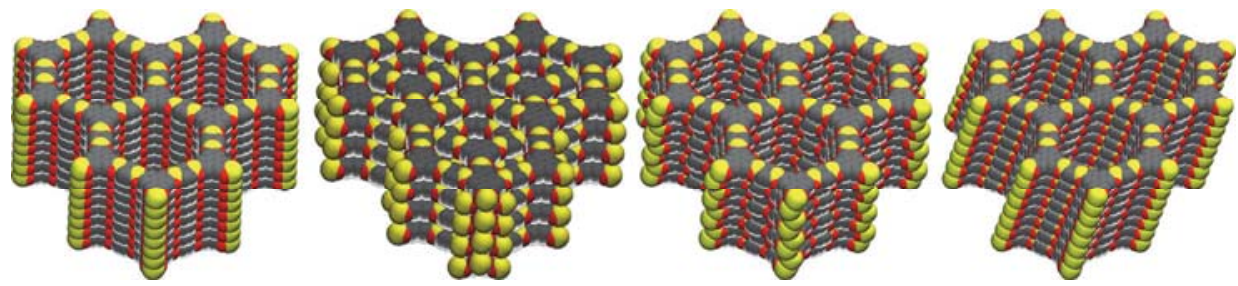

图 2 二维 $\mathrm{COM}$ 材料的堆垛模式: 高对称的 eclipsed AA、staggered $\mathrm{AB}$ 堆垛模式和低对称的 serrated、inclined 堆垛模式(从左至右) ${ }^{[67]}$

Figure 2 The packing model of COM materials: high-symmetry eclipsed AA and staggered AB stacking form, and low-symmetry serrated and inclined stacking form (from left to right) ${ }^{[67]}$ 
的 $\mathrm{COFs}^{[73]}$. 离域的电子从石墨烯进入到 $\mathrm{COF}$ 的 HOMO-LOMO 能级有助于 COFs 在石墨烯表面上的自 组装过程, 也产生了轨道之间的强烈交互作用, 使得 $\mathrm{COF}$ 材料以平面的形式生长在石墨烯表面上.

\section{3 半导体 COM 材料}

到目前, 许多具有半导体和导体性能的 COMs 材料 已经合成出来, 并用于相应的光电器件上, 大体集中在 多并苯、卟啉、酞菁、噻吩类有序 $\mathrm{COF}$ 材料, 在本小节 中, 将逐一详细介绍.

\section{1 多并苯类}

2008 年, Jiang 课题组 ${ }^{[74]}$ 通过 2,3,6,7,10,11-六羟基三 亚苯(HHTP)和 2,7-二硣酸萠(PDBA)的缩合反应(图 3a), 合成了一种具有苂光性、半导体性质的 COF 材料: TP-COF. TP-COF 的 BET 比表面积为 $868 \mathrm{~m}^{2} \cdot \mathrm{g}^{-1}$, 孔体 积为 $0.79 \mathrm{~cm}^{3} \cdot \mathrm{g}^{-1}$, 孔径大小为 $3.14 \mathrm{~nm}$. 采用两探针法, 测试材料的半导体性能. 通常对于半导体材料的 $I-V$ 曲 线会呈线性关系. 在室温条件下, 通过将 TP-COF 材料 在丙酮分散滴涂在 $10 \mu \mathrm{m}$ 宽的铂电极上, 测试的 $I-V$ 曲 线近似为线性关系, 而不含有 TP-COF 材料的 $I-V$ 曲线
电流值恒定为零(图 3b), 表明 TP-COF 材料具有半导体 性能. 碘负载的 TP-COF 的电流增加, 表明 TP-COF 为 $\mathrm{P}$ 型半导体. 此外, 在外加偏压 $2 \mathrm{~V}$ 的条件下, 其电流达 到 $4.3 \mathrm{nA}$, 远大于单体 HHTP : PDBA (2:3)混合物的 $79 \mathrm{pA}$, 说明通过 $\pi$ 堆垛的共轭体系会大大提高材料的本 征半导体性质. 经重复进行电流开关实验, 发现电流值 几乎没有衰减(图 3c), 具有良好的电学稳定性.

为了获得光致导电性能, Jiang 课题组通过 2,7-二硼 酸萠(PDBA)自缩聚反应制备出 PPy-COF 材料(图 3d $)^{[75]}$. PPy-COF 材料能吸收可见光，在可见光辐射下能快速产 生光电流. 通过光电性能测试, 在波长为 $414 \mathrm{~nm}$ 光的辐 射下, PPy-COF 能激发 $484 \mathrm{~nm}$ 的波长. PPy-COF 材料也 表现出半导体特性, 碘掺杂后, 电流增加, 表明 PPy-COF 材料为空穴传播材料. 光致导电器件, 通过将 PPy-COF 分散在聚甲基丙烯酸甲酯(PMMA)溶液中, 形 成 $100 \mu \mathrm{m}$ 厚的薄膜, 制备 $\mathrm{Al} / \mathrm{PPy}-\mathrm{COF} / \mathrm{Au}$ 三明治结构 的光电器件, 在氙灯的照射下, PPy-COF 高度响应, 得 到一条快速增长的线性 $I-V$ 曲线(图 3e). 此外, 在 $8.0 \times$ $10^{4}$ 次的重复光电开关测试中, 光电流没有出现很大的 衰减, 呈现出良好的稳定性(图 3f). (a)

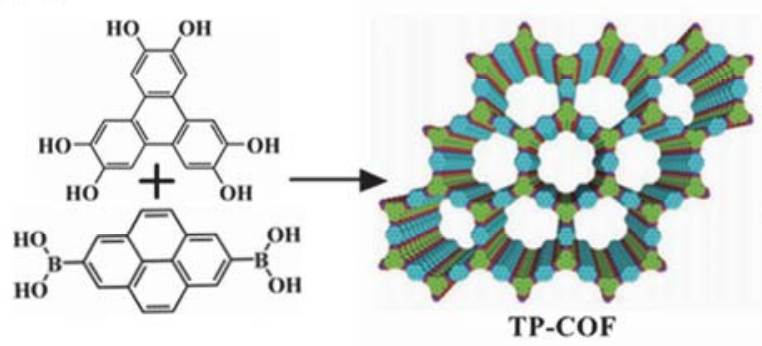

(d)

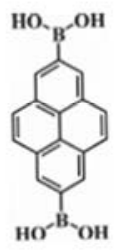

(b)

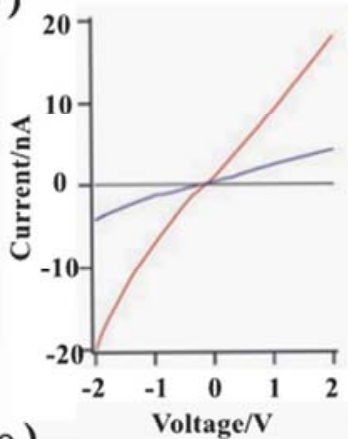

(e)
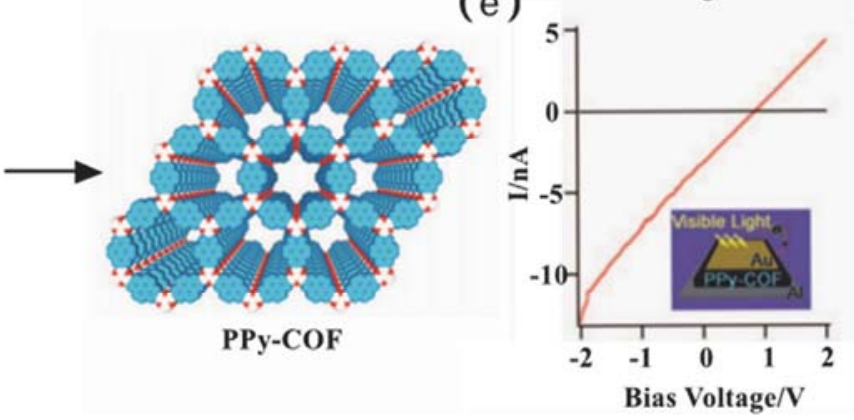

(c)

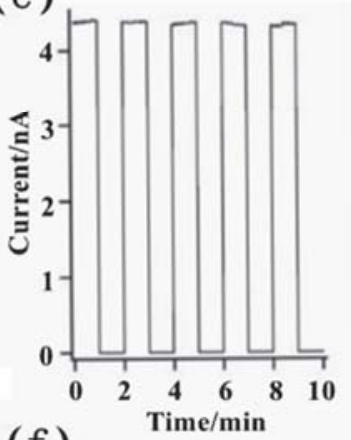

(f)

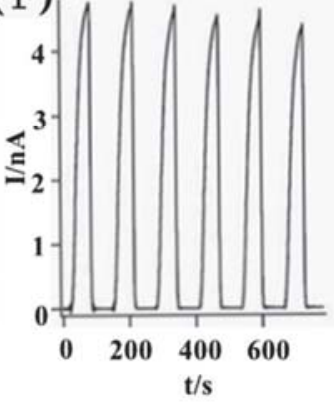

图 3 (a) TP-COF 合成和结构示意图(结构中, B 紫色, $\mathrm{O}$ 红色, triphenylene 绿色, pyrene 蓝色, 氢原子省略); (b) $10 \mu \mathrm{m}$ 宽的铂片间隔器件所测的 $I-V$ 曲线(黑线: 无 TP-COF; 蓝线: 有 TP-COF; 红线: 掺碘的 TP-COF); (c)偏压为 $2 \mathrm{~V}$ 时的开关电流. (d) PPy-COF 合成和结构示意图. (结构中, B 白色, $\mathrm{O}$ 红色, pyrene 蓝色, 氢原子省略); (e)三明治结构 $(\mathrm{Al} / \mathrm{PPy}-\mathrm{COF} / \mathrm{Au}$ )器件的 $I-V$ 曲线(黑色: 无光照; 红色: 有光照); (f)光照下的开关电流

Figure 3 (a) Schematic representation of TP-COF (structure is based on quantum calculation and crystal lattice parameters; B purple, O red, triphenylene green, pyrene blue, $\mathrm{H}$ atoms are omitted for clarity). (b) $I-V$ profile of a $10 \mu \mathrm{m}$ width Pt gap (black curve: without TP-COF; blue curve: with TP-COF; red curve: with iodine-doped TP-COF). (c) Electric current when $2 \mathrm{~V}$ bias voltage is turned on or off. (d) Schematic representation of the structure of $\mathrm{PPy}-\mathrm{COF}$. The structure is based on quantum-chemical calculations and crystal-lattice parameters (B white, $\mathrm{O}$ red, pyrene blue; $\mathrm{H}$ atoms are omitted for clarity). (e) $I-V$ profile of PPy-COF between sandwich-type Al/Au electrodes (black curve: without light irradiation; red curve: upon light irradiation). (f) Photocurrent when the light was turned on or off 


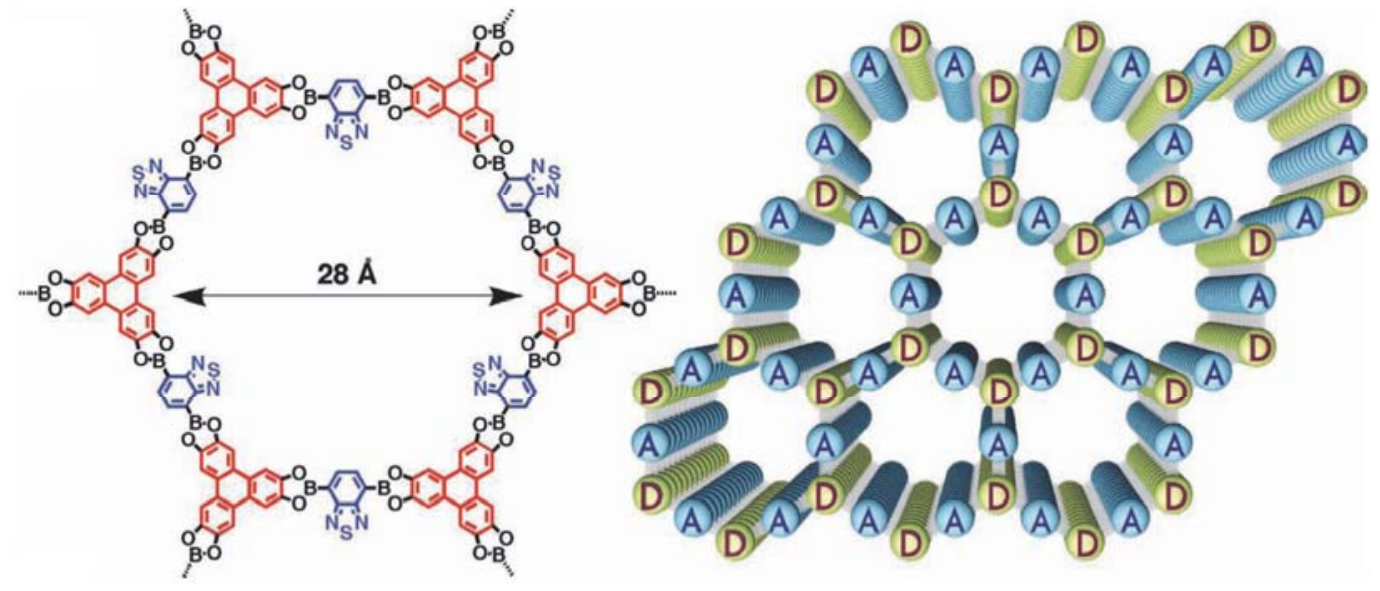

图 4 D-A-COF 结构示意图 ${ }^{[76]}$

Figure 4 D-A-COF co-condensed from benzothiadiazole diboronic acid and HHTP ${ }^{[76]}$

Feng 等 ${ }^{[76]}$ 通过 HHTP 和苯并噻二唑二硼酸缩聚(图 4), 制备了一种双极导电的 D-A-COF 材料. 电子能沿着 苯并噻二唑单元构成的通道传输, 而空穴沿着 HHTP 构 成的通道传输, 电子和空穴迁移率分别为 0.04 和 0.01 $\mathrm{cm}^{2} \cdot \mathrm{V}^{-1} \cdot \mathrm{s}^{-1}$.

\section{2 酞菁、卟啉类}

酞菁类分子因具大平面共轭体系, 具有较强吸光性 能, 被广泛地用于光电领域. 2010 年, Dichtel 课题组 ${ }^{[77]}$ 报道了由酞菁骨架构建的 Pc-PBBA COF(图 5a), 具有较 宽的光谱响应范围, 能够吸收至 $1250 \mathrm{~nm}$ 的近红外光 (图 5b). 2011 年, Jiang 课题组 ${ }^{[78]}$ 用 $\left[(\mathrm{OH})_{8} \mathrm{PcNi}\right]$ 和对苯二 嗍酸(1,4-benzenediboronicacid: BDBA)反应合成了 NiPc $\mathrm{COF}$ (图 5c). 这种材料具有大的 $\pi$ 共轭体系和层状叠加 排列结构, 有利于电荷的运输与转移. NiPc COF 材料的 孔径为 $1.9 \mathrm{~nm}$, 比表面积是 $624 \mathrm{~m}^{2} \cdot \mathrm{g}^{-1}$, 孔体积为 $0.4854 \mathrm{~cm}^{3} \cdot \mathrm{g}^{-1}$. NiPc COF 能吸收可见光和近红外光的 光子, 具有良好的吸光能力. NiPc COF 在氙灯的照射 下, 偏压 $1 \mathrm{~V}$ 时产生的电流从 $20 \mathrm{nA}$ 增加到 $3 \mu \mathrm{A}$, 并且 能进行重复性电流开关切换, 光电流并没有减弱. $\mathrm{Au} / \mathrm{NiPc} \mathrm{COF} / \mathrm{Al}$ 三明治结构的器件, 在传导测试中发 现 $I-V$ 曲线呈线性关系(图 5d), 说明 $\mathrm{NiPc} C \mathrm{COF}$ 具有半导 体的特性.

为了制备电子传输型的 COM 材料, Jiang 课题组 ${ }^{[79]}$ 采用取电子基团苯并噻二唑二硼酸和酞菁 $\mathrm{Ni}$ 环 $\left[(\mathrm{OH})_{8} \mathrm{PcNi}\right]$ 缩聚, 合成出第一个电子传输的 $\mathrm{COF}$ 材料, 即 2D-NiPc-BTDA COF(图 5e). 2D-NiPc-BTDA COF 表 现出很强的光导性, 采用瞬时光照微波传导测试方法证 实了电子的传输, 电子迁移率为 $0.6 \mathrm{~cm}^{2} \cdot \mathrm{V}^{-1} \cdot \mathrm{s}^{-1}$. 在氞 气的氛围中, $355 \mathrm{~nm}$ 的激光以 $1.6 \times 10^{15}$ 的光电流密度照 射下, 测得总的载流子迁移率为 $5.8 \times 10^{-4} \mathrm{~cm}^{2} \cdot \mathrm{V}^{-1}$ • $\mathrm{s}^{-1}$ (图 5f), 电子和空穴的瞬间迁移导致总的载流子迁移 率出现双指数的衰减, 第一次加速衰减是在 $\mathrm{SF}_{6}$ (电子猝
灭剂)的氛围内测试, 再在 $\mathrm{SF}_{6}$ 或者氧气低温退火, 主要 是因为电子的迁移导致载流子迁移率迅速地衰减; 第二 次衰减几乎不受 $\mathrm{SF}_{6}$ 和氧气低温退火的影响, 此时的空 穴迁移率是 $2.9 \times 10^{-5} \mathrm{~cm}^{2} \cdot \mathrm{V}^{-1} \cdot \mathrm{s}^{-1}$. 他们 ${ }^{[80]}$ 进一步以酞 菁作为电子供体, 菜四羧酸酰亚胺作为电子受体, 合成 了一种双极半导体: $\mathrm{D}_{\mathrm{ZnPc}}-\mathrm{A}_{\mathrm{NDI}}-\mathrm{COF}$ (图 5g), 采用时间分 辨光谱的方法揭示了电子从产生到离域, 以及停留的过 程. $\mathrm{D}_{\mathrm{ZnPc}}-\mathrm{A}_{\mathrm{NDI}}-\mathrm{COF}$ 能够在 $2 \mathrm{ps}$ 内快速的实现自由电子 的激发并从供体传输到受体的过程.

与酞菁类似的卟啉环单元, 在光电 $\mathrm{COF}$ 材料的构 建中也起到了非常重要的作用. 2011 年, Yaghi 课题组 ${ }^{[81]}$ 采用希夫碱反应，由卟啉分别和对苯二甲醛\&四甲醛葱 缩聚合成出 COF-366(图 6a)和 COF-66(图 6b)材料. 以氧 化锡铟和铝为电极, 中间夹层为 $1.5 \mu \mathrm{m}$ 的 $\mathrm{COF} /$ 异丁烯 酸甲酯 $(60: 40 \mathrm{wt} \%)$ 的三明治器件, 采用微波电导率的 实验方法测得二者的空穴迁移率高达 8.1 和 $3.0 \mathrm{~cm}^{2}$. $\mathrm{V}^{-1} \cdot \mathrm{s}^{-1}$. 研究表明二维的吓啉基 $\mathrm{COF}$ 材料的电子传输 速率不仅和卟啉的大环骨架结构有关, 还和卟啉大环中 心耦合的离子有关. Jiang 等 ${ }^{[82}$ 合成了三种中心位点不 同的二维 MP-COFs 材料, 分别为 $\mathrm{H}_{2} \mathrm{P}-\mathrm{COF} 、 \mathrm{ZnP}-\mathrm{COF}$ 和 CuP-COF(图 6e). ZnP-COF 的电子传输速率和空穴迁 移速率分别为 $5.4 \times 10^{-5}$ 和 $3.36 \times 10^{-5} \mathrm{~cm}^{2} \cdot \mathrm{V}^{-1} \cdot \mathrm{s}^{-1}$, 二 者相差不大, $\mathrm{ZnP}-\mathrm{COF}$ 材料可以作为两性导电材料, 而 $\mathrm{CuP}-\mathrm{COF}$ 的电子传输速率大于空穴迁移速率, $\mathrm{CuP}-\mathrm{COF}$ 材料可以作为电子导电材料. $\mathrm{H}_{2} \mathrm{P}-\mathrm{COF}$ 的电子传输速率 小于空穴迁移速率, $\mathrm{H}_{2} \mathrm{P}-\mathrm{CO}$ 材料可以作为电子导电材 料. 在氙灯的照射下, 三种 $\mathrm{COF}$ 材料均会产生光电流, 且三者的光电流相差很大, $\mathrm{ZnP}-\mathrm{COF}$ 产生的光电流约为 $26.8 \mathrm{nA}, \mathrm{CuP}-\mathrm{COF}$ 和 $\mathrm{H}_{2} \mathrm{P}-\mathrm{COF}$ 产生的光电流分别为 0.6 和 $0.01 \mathrm{nA}$ (图 6f). $\mathrm{ZnP}-\mathrm{COF}$ 具有最大的光开关电流值 $5 \times 10^{4}$, 分别是 $\mathrm{H}_{2} \mathrm{P}-\mathrm{COF}$ 和 CuP-COF 的 150 倍和 1000 倍. 因此, 材料中卟啉环中的金属原子有着重要的作用, 


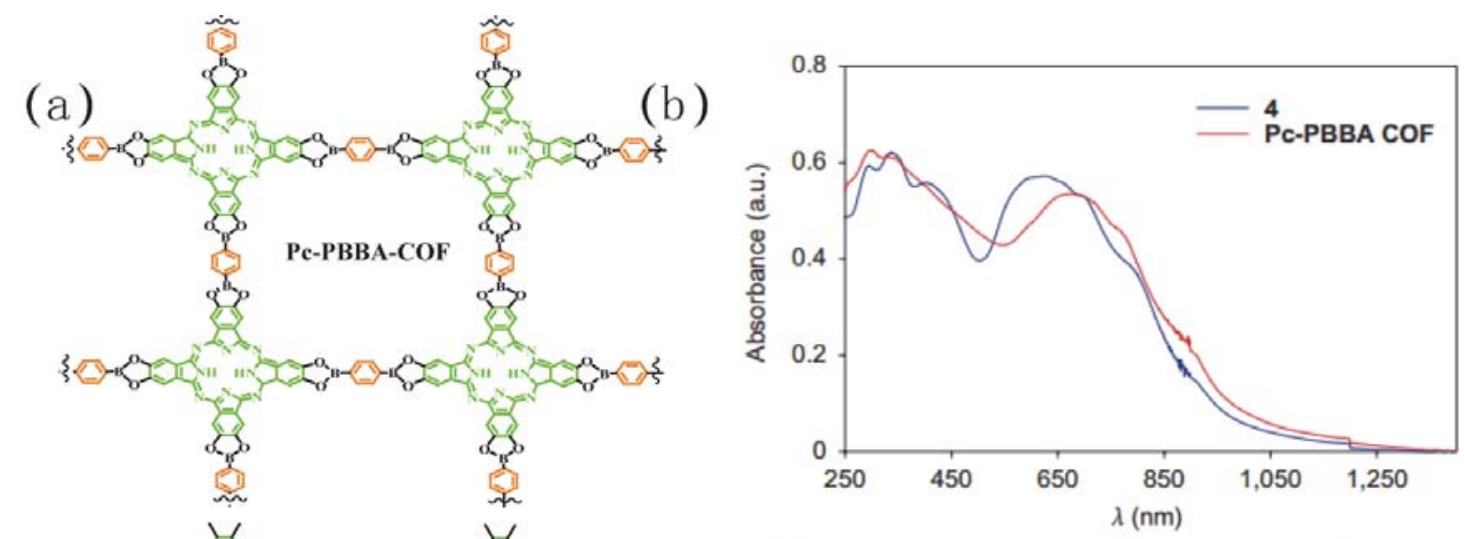

(c)

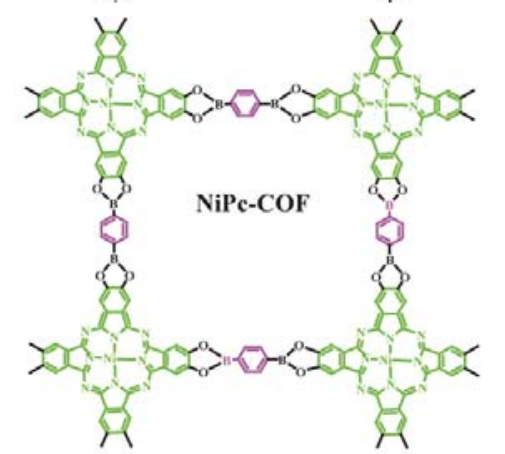

(e)
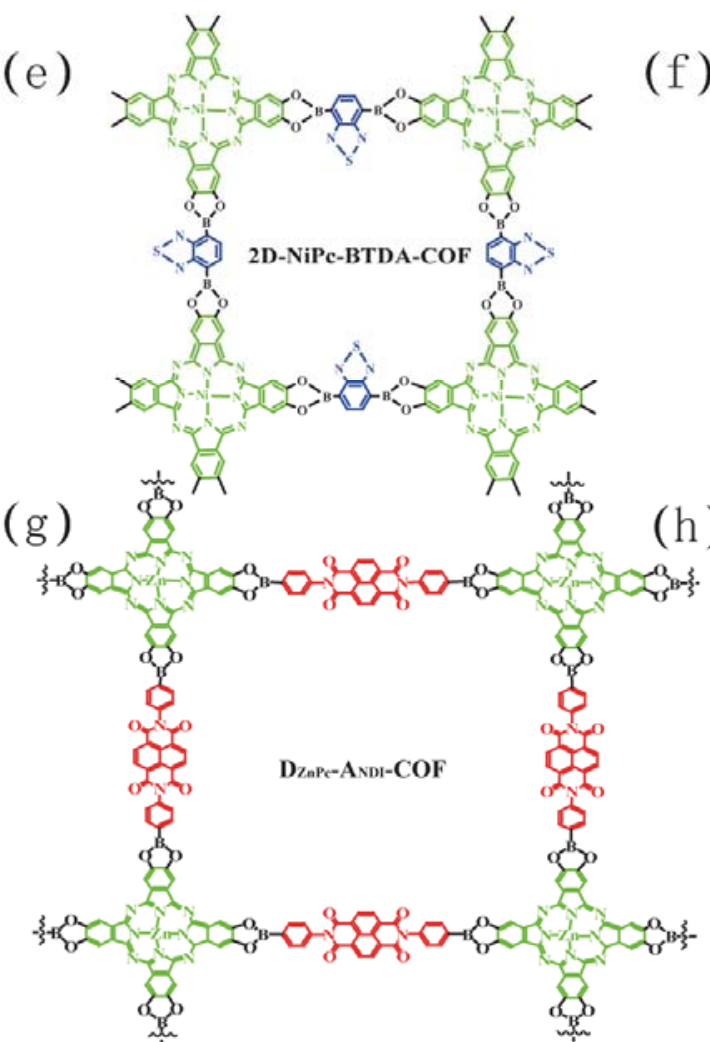

(d)
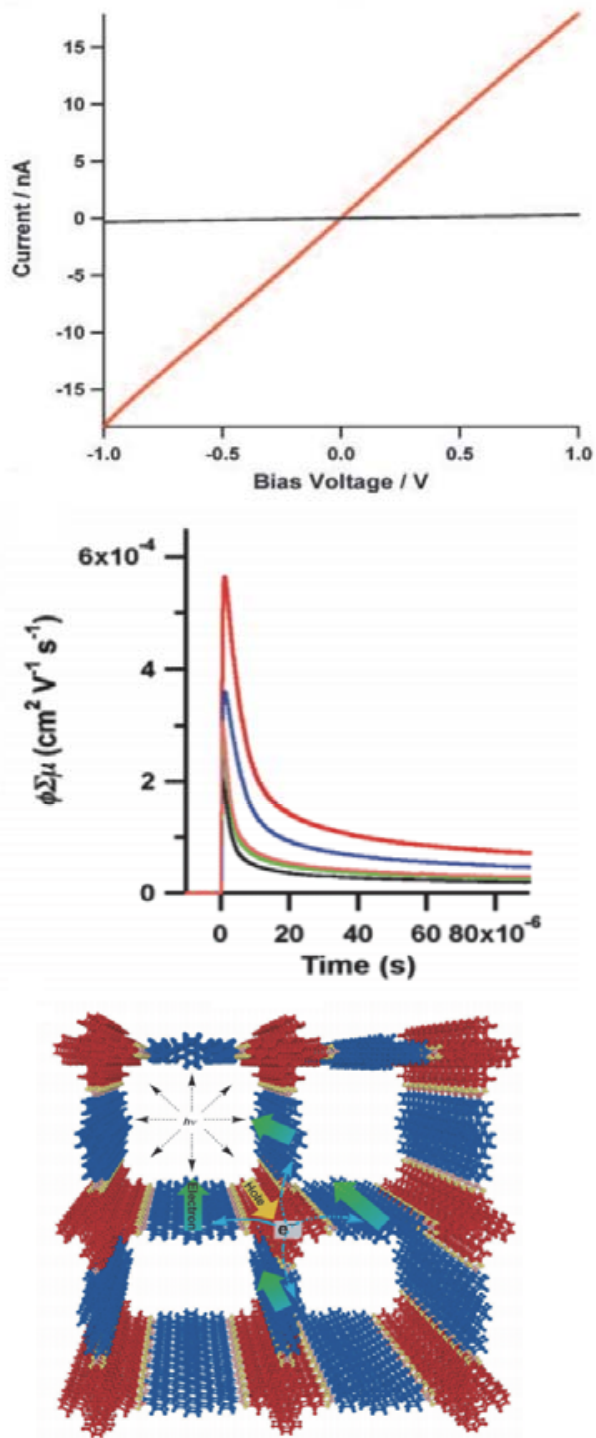

图 5 (a) Pc-PBBA COF 的结构图; (b) Pc-PBBA COF 在可见光和近红外光的吸光谱图; (c) NiPc COF 的结构图; (d) 以 NiPc COF(红线)和 $\left[(\mathrm{MeO})_{8} \mathrm{PcNi}\right.$ (黑线)为夹层铝金为电极材料的三明治器件的 $I-V$ 曲线; (e) $2 \mathrm{D}-\mathrm{NiPc}-\mathrm{BTDA} \mathrm{COF}$ 的结构图示; (f)光电流密度为 $1.6 \times 10^{15}, 355 \mathrm{~nm}$ 的脉 冲激光照射, 氩气(红线), $\mathrm{SF}_{6}$ (蓝线)气氛下, 以及 $\mathrm{SF} 6$ 气氛退火 $1 \mathrm{~h}$ (橙线), $24 \mathrm{~h}$ (绿线), 氧气气氛退火 $24 \mathrm{~h}$ (黑线)时的瞬时电导率; ( $\mathrm{g}$ ) $\mathrm{D}_{\mathrm{ZnPc}}-\mathrm{A}_{\mathrm{NDI}}-\mathrm{COF}$ 的结构图示; (h) $2 \times 2$ 超晶格, 层距为 $0.8 \AA$ 的 $\mathrm{AA}$ 堆垛模式结构图和其光化学过程示意图

Figure 5 (a) Schematic representation of Pc-PBBA COF. (b) Pc-PBBA COF absorbs light over a broad range of the visible and near-infrared spectral regions. (c) Schematic representation of NiPc COF. (d) $I-V$ curves of NiPc COF (red curve) and $\left[(\mathrm{MeO})_{8} \mathrm{PcNi}\right]$ (black curve) sandwiched between $\mathrm{Al} / \mathrm{Au}$ electrodes. (e) Schematic representation of 2D-NiPc-BTDA COF. (f) Transient conductivities irradiated with a $355 \mathrm{~nm}$ pulsed laser at the photon density of $1.6 \times 10^{15}$ under $\mathrm{Ar}$ (red curve), $\mathrm{SF}_{6}$ (blue curve), and after annealing under $\mathrm{SF}_{6}$ for $1 \mathrm{~h}$ (orange curve) and $24 \mathrm{~h}$ (green curve) or under $\mathrm{O}_{2}$ for $24 \mathrm{~h}$ (black curve). (g) Schematic representation of $\mathrm{D}_{\mathrm{ZnP}}-\mathrm{A}_{\mathrm{NDI}} \mathrm{COF}$; (h) Illustration of a $2 \times 2$ cell of the $0.8 \AA$ slipped $\mathrm{AA}$-stacked COFs and photochemical events 

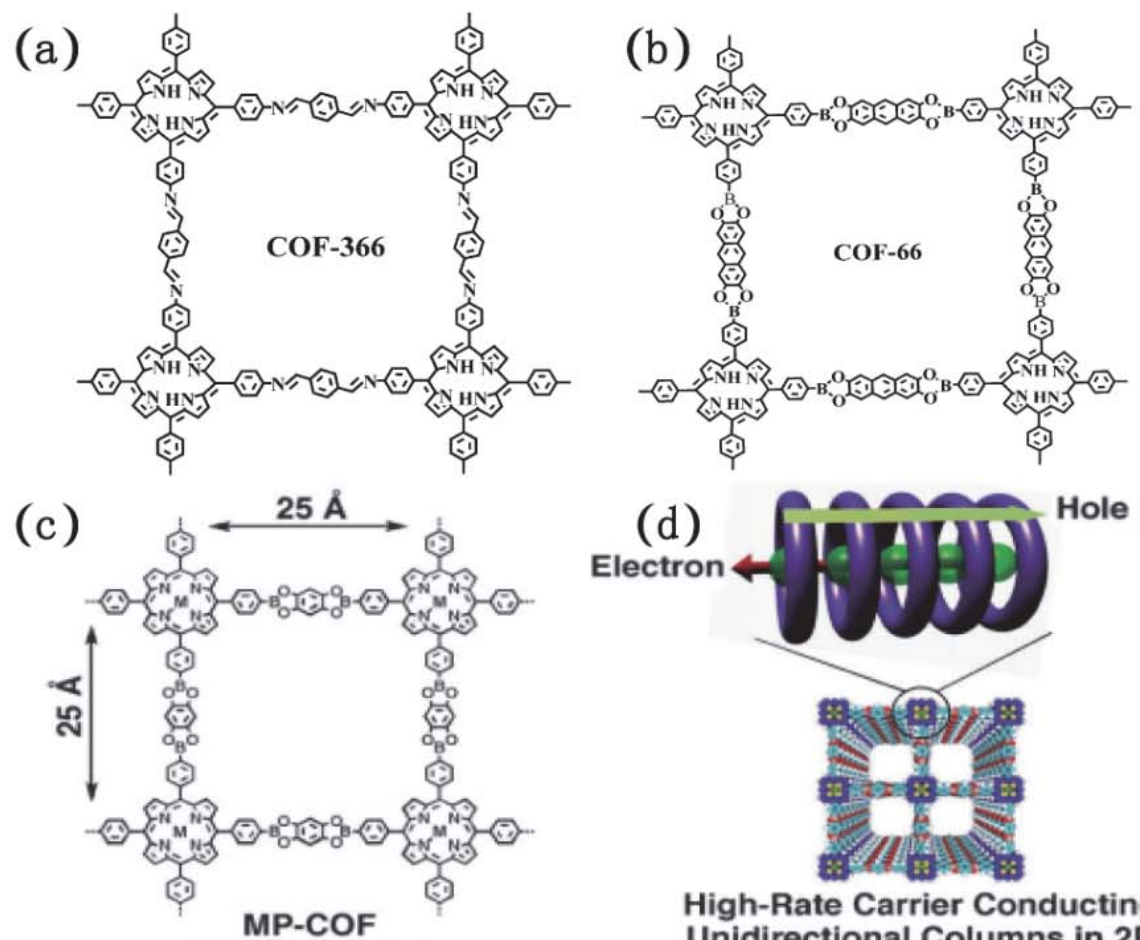

(e) $\left(\mathrm{M}=\mathrm{H}_{2}, \mathrm{Zn}, \mathrm{Cu}\right)$

High-Rate Carrier Conducting Unidirectional Columns in 2D Porphyrin COFs

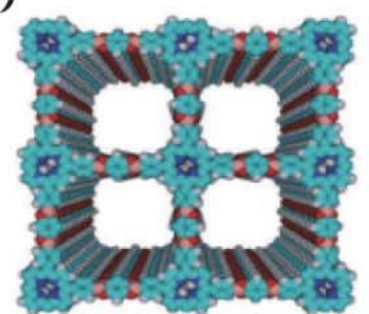

$\mathrm{H}_{2} \mathrm{P}-\mathrm{COF}$

几

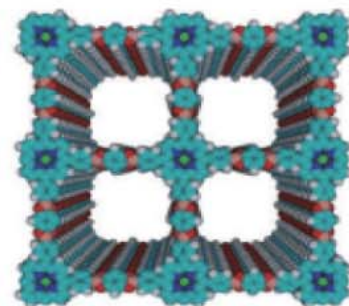

ZnP-COF

$\sqrt{1}$

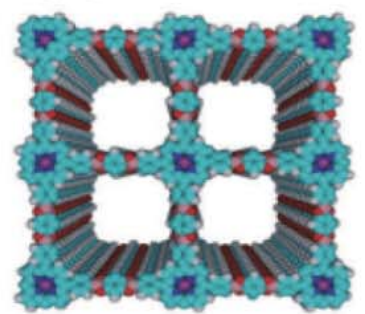

CuP-COF

ل]

Electron
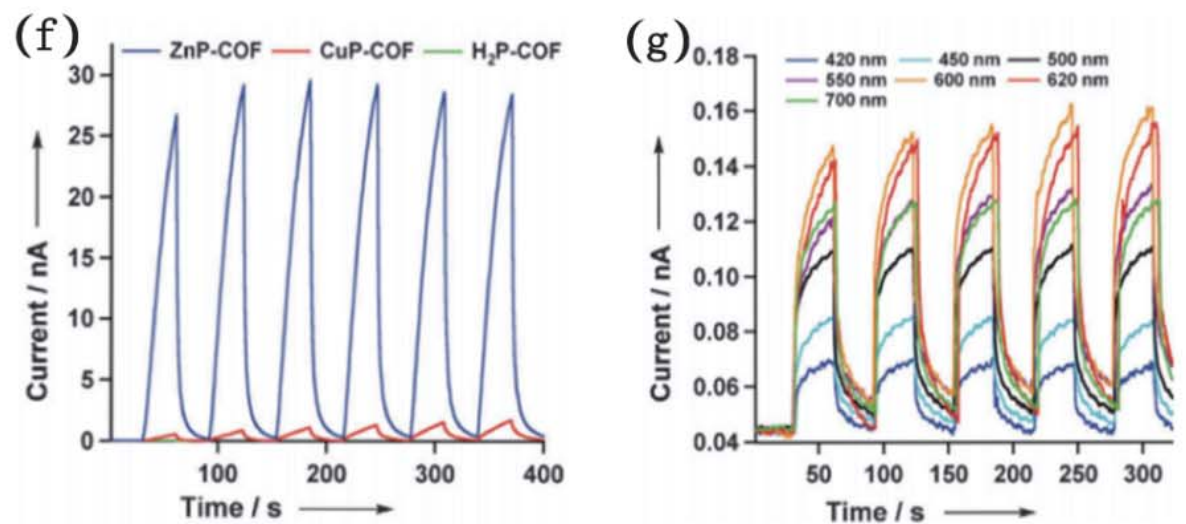

图 6 (a) COF-366 的结构示意图; (b) COF-66 的结构示意图; (c) MP-COFs 示意图(M= $\mathrm{H}_{2}, \mathrm{Zn}$ 和 Cu); (d)非手性层层堆积的二维 MP-COFs 材料含 有 $2 \times 2$ 超级晶格示意图(碳: 亮蓝色; 氮: 深蓝色; 氢: 白色: 氧: 红色; 嗍: 粉色; 锌: 绿色; 铜: 紫色); (e)二维柱状形卟啉 COF 上, 金属对金属 和大环对大环通道表示的电子传输和空穴传输图示; (f)二维卟啉 COFs 光照下的重复开关电流; (g) ZnP-COF 在偏压 $1.0 \mathrm{~V}$ 不同波长光照下的开关 电流

Figure 6 (a) Schematic representation of COF 366. (b)Schematic representation of COF 66. (c) Schematic representation of MP-COFs $\left(\mathrm{M}=\mathrm{H}_{2}, \mathrm{Zn}\right.$, and $\mathrm{Cu}$ ). (d) Schematic graphs of a $2 \times 2$ grid of MP-COFs with achiral AA stacking 2D sheets (C: light blue; N: deep blue; H: white; O: red; B: pink; Zn: green; $\mathrm{Cu}$ : violet). (e) Graphical representation of metal-on-metal and macrocycle-on-macrocycle channels for respective electron and hole transport in stacked porphyrin column of 2D porphyrin COF. (f) Photocurrents for 2D porphyrin COFs upon repeated switching of the light on and off. (g) Wavelength-dependent on-off switching of photocurrent of $\mathrm{ZnP}-\mathrm{COF}$ at a bias voltage of $1.0 \mathrm{~V}$ 
在一定程度上影响 $\mathrm{COF}$ 材料中电子的迁移方式, 从而 影响材料的整体性质.

\section{3 噻吩类}

噻吩是一种重要的单体用于合成错综复杂的有机 聚合物. 噻吩弯曲的单体结构可以有效地调控 COM 材 料的构型, 然而对于需要一定晶型、具有传导功能的 COM 材料来说, 弯曲的结构会影响结构内部的电子传 输, 消弱材料的传导性能. 为了克服这个困难, Bertrand 等 ${ }^{[83]}$ 采用一种连接两个噻吩分子在一个反并联的构型 中, 可以形成一种线性且具有高度晶型的 COFs. 他们 采用这种方法合成的 4 种含有噻吩基的 COFs 材料分别 为 T-COF-1, T-COF-2, T-COF-3 和 T-COF-4(图 7a). 他们 采用噻吩硼酸单元和醌二甲烷证实了电子转移的过程,
但是并没有发现电子从 $\mathrm{COF}$ 转移到醌二甲烷的过程. Bein 和 Knochel 等 ${ }^{[84]}$ 采用 thieno[3,2- $b$ ] thiophene2,5-diyldiboronic acid (TTBA) 和 HHTP 合成了能够作为 电子供体的噻吩基 TT-COF. TT-COF 的具有较大的比表 面积和开放的多孔通道使得它能够作为电子传输的材 料, TT-COF 能够与电子受体 [6,6]-phenyl-C61-butyric acid methyl ester (PCBM)构成一种新的结构有序的电子 供体一受体体系, 光谱分析证实了光诱导激发产生的电 子从 TT-COF 进入到 PCBM 的多孔通道中的过程. 而利 用 TT-COF 和 PCBM 制作的光伏器件能够测得开路电压 $622 \mathrm{mV}$, 短路电流密度为 $0.213 \mathrm{~mA} \cdot \mathrm{cm}^{-2}$ (图 7b), 这些 结果也说明了 TT-COF 光电传导的特性, 具有一定的有 机光伏器件应用潜力. (a)
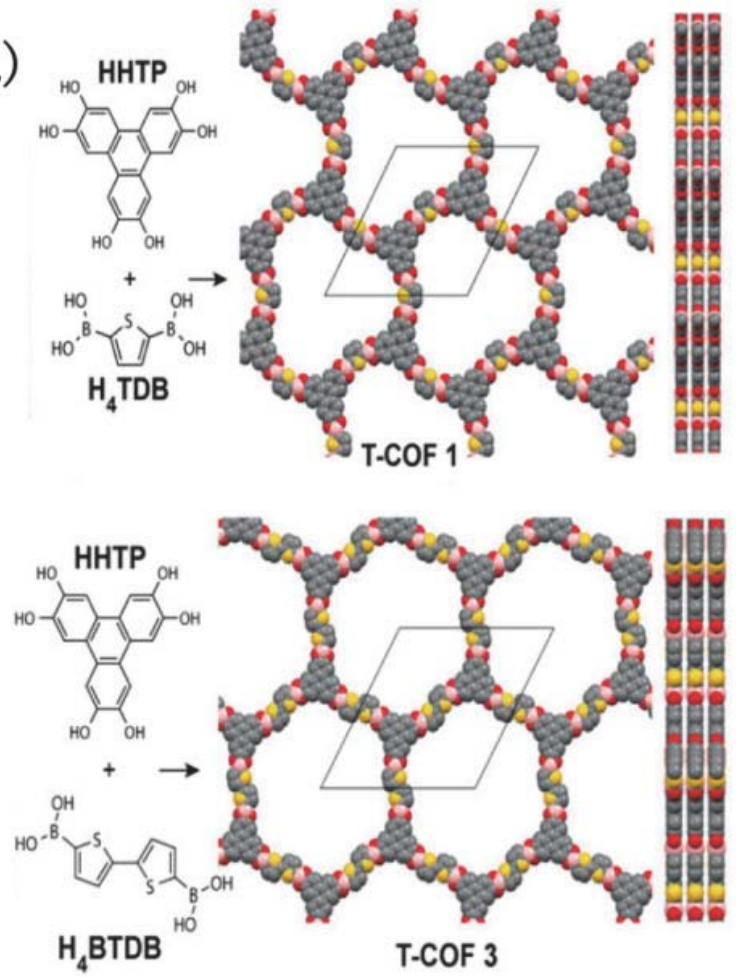

(b)

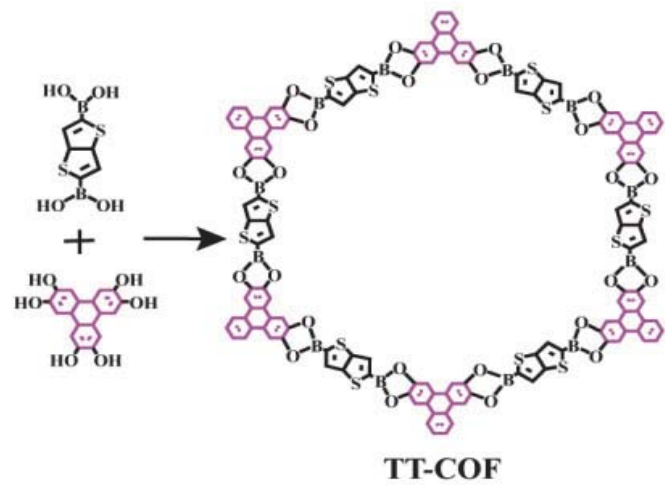

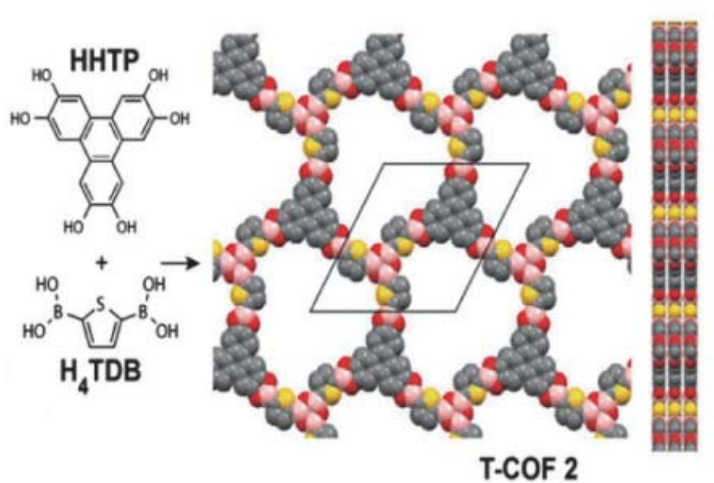
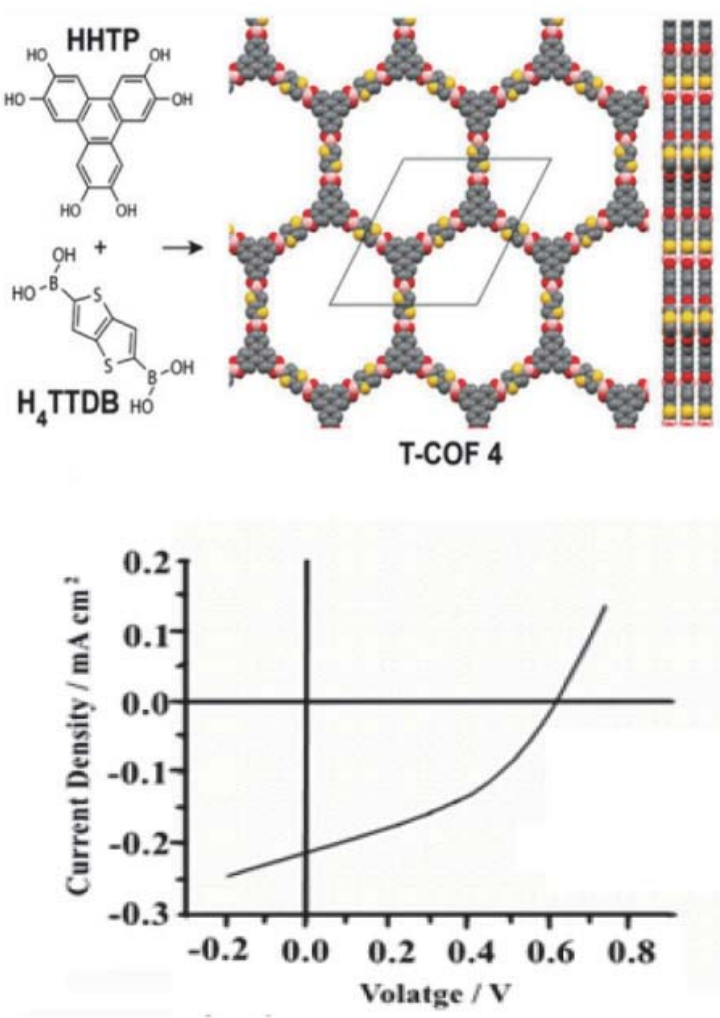

图 7 (a) T-COF 1,2,3,4 的构筑单元和结构示意图; (b) TT-COF 的共缩聚合成过程和模拟太阳光照射下 TT-COF 太阳能电池的 $I-V$ 曲线

Figure 7 (a) Building blocks and the partial structure viewed normal and parallel to the AB plane of T-COF 1,2,3,4. (b) Reaction scheme for the co-condensation of TT-COF and $I-V$ characteristics of the TT-COF-based photovoltaic cell measured under illumination with simulated solar light 


\section{4 能源 COM 材料}

利用上述 $\mathrm{COM}$ 材料的本征半导体性能, 可以设计 制作相应的能源器件, 如光解水和太阳能电池. 除此之 外, COM 材料也是一类丰富的可调模板材料, 经过高温 裂解, 可以制备很多多功能高活性的电催化与储能材 料, 如在氧还原、锂电、锂硫电池以及超级电容等领域 也有着广泛的应用, 下面将分别详细总结近年来 $\mathrm{COM}$ 材料在这些领域中的应用. 此外, 值得一提的是: 作为 氧还原、锂电、锂硫电池和超级电容器等器件的电极材 料, 均需要材料具有良好的本征导电性. 而目前大部分 报道的 COM 材料表现出的是半导体特性, 本征导电性 较差. 因此, 当前大部分工作是以 COM 材料为前驱体, 经高温碳化提高其导电性. 而高温碳化过程可能会破坏 COM 材料原始的规则可控结构, 给衍生碳材料结构的 表征带来了很大的挑战. 合成具有良好的本征导电性的 COM 材料, 有利于借助可控的化学调控手段, 定向调 控材料的性能，更容易实现光电材料的 “私人定制” .

\section{1 光解水}

光催化分解水制氢(光解水)一直是研究关注的焦 点, 光催化能把太阳能转化为化学能, 而能够有效地将 光能转化为化学能的光催化剂是实现太阳能光催化分 解水制氢的关键. 对于半导体材料, 光辐射在半导体上, 当辐射的能量大于或相当于半导体的禁带宽度时, 半导 体内的电子受激发从价带 $(\mathrm{VB})$ 跃迁到导带 $(\mathrm{CB})$, 从而在 导带和价带分别产生自由电子 $\left(\mathrm{e}^{-}\right)$和电子空穴 $\left(\mathrm{h}^{+}\right)$, 然 后发生光氧化还原反应. 其中电子具有还原性, 当电子 的电势比 $\mathrm{H}^{+} / \mathrm{H}_{2}$ 电势更负时, 就可能将水还原成氢气; 产生的空穴具有氧化性, 当空穴的电势比 $\mathrm{O}_{2} / \mathrm{H}_{2} \mathrm{O}$ 的电 势更正时, 就可能将水氧化成氧气 ${ }^{[85]}$, 其过程如图 8 所 示.

除金属氧化物半导体 ${ }^{[86]}$ 材料外，一种类似于石墨 烯的层状材料: 氮化碳 $\left(\mathrm{g}-\mathrm{C}_{3} \mathrm{~N}_{4}\right)$ 材料也被广泛地用于光
裂解水中 ${ }^{[87]} \cdot \mathrm{g}-\mathrm{C}_{3} \mathrm{~N}_{4}$ 是以三均三嗪为基本连接单元形成 的共价有机结构，是一类类石墨烯结构的层状 COM 材 料, 具有良好的化学稳定性和热稳定性, 它的带宽是 $2.7 \mathrm{eV}$, 可以吸收太阳光谱中波长小于 $475 \mathrm{~nm}$ 的蓝紫 光，在催化领域表现出广阔的应用前景.

2008 年, Wang 课题组 ${ }^{[88]}$ 以三均三嗪(tri-s-triazine) 为基本连接单元形成 $\mathrm{g}-\mathrm{C}_{3} \mathrm{~N}_{4}$ (图 9a), 发现其在可见光的 照射下可催化水的光解, $\mathrm{g}-\mathrm{C}_{3} \mathrm{~N}_{4}$ 能够吸收到 $540 \mathrm{~nm}$ 左右 的可见光(图 9b). $\mathrm{g}-\mathrm{C}_{3} \mathrm{~N}_{4}$ 单独进行光解水时, 产氢速率 只有 $0.1 \sim 4 \mu \mathrm{mol} \cdot \mathrm{h}^{-1}$, 光解水的效率也很低. 之后, 在 $\mathrm{g}-\mathrm{C}_{3} \mathrm{~N}_{4}$ 结构中载入 $\mathrm{Pt}$ 纳米颗粒修饰, 其产氢速率明显提 高. 反应 $72 \mathrm{~h}$ 后, 总产氢量达到 $770 \mu \mathrm{mol}$, 且保持良好 的稳定性. 为进一步提高产氢量, Wang 课题组 ${ }^{[89]}$ 又以 介孔二氧化硅为模板合成介孔 $g-\mathrm{C}_{3} \mathrm{~N}_{4}\left(\mathrm{mpg}-\mathrm{C}_{3} \mathrm{~N}_{4}\right)$, 因其 具有大比表面和多次散射的作用, 故 $m p g-\mathrm{C}_{3} \mathrm{~N}_{4}$ 的光解 水的效率有很大的提高. $\mathrm{mpg}^{-} \mathrm{C}_{3} \mathrm{~N}_{4}$ 材料的 BET 比表面 积分布从 $37 \sim 373 \mathrm{~m}^{2} \cdot \mathrm{g}^{-1}$. 当将 $3 \%$ 的 $\mathrm{Pt}$ 纳米颗粒与 $m p g-\mathrm{C}_{3} \mathrm{~N}_{4}$ 复合后, 光解水产氢的速率提高到 $149 \mu \mathrm{mol}$ • $\mathrm{h}^{-1}$. 反应 $25 \mathrm{~h}$ 后, 总产氢量达到 $3.5 \mathrm{mmol}$.

2010 年, Ye 课题组 ${ }^{[90]}$ 报道了用氮掺杂的钽酸敏化 氮化碳聚合物, 吸收光谱红移, 可吸收可见光. 在可见 光的照射下掺杂的氮化碳也有良好的制氢能力，在 420 $\mathrm{nm}$ 下量子产率可以达到 4.8\%. 2014 年, Wang 等 ${ }^{[46]}$ 报道 了二维的共轭聚合物 $\mathrm{g}-\mathrm{CN}$ 半导体, 这种低维度的氮化 碳通过芳香异构结构来改性. 四种典型的有机处理剂, barbituric acid (BA), 2-aminobenzonitrile (ABN), 2-aminothiophene-3-carbonitrile (ATCN) 和 diaminomaleonitrile (DAMN)被选做共聚单体与氮化碳前驱体缩 合, 将简单的尿素经高温得到改性的主体氮化碳纳米 片. 改性的 $\mathrm{g}-\mathrm{CN}$ 吸收光子波长向红光方向移动, 范围 扩大为 $460 \sim 600 \mathrm{~nm}$, 提高了光的吸收能力, 且电荷分 离和转移率也有很大提高. 掺杂噻吩的 CNU-ATCN, 产 氢率是密集主体氮化碳的 74 倍, 在 $420 \mathrm{~nm}$ 的光下

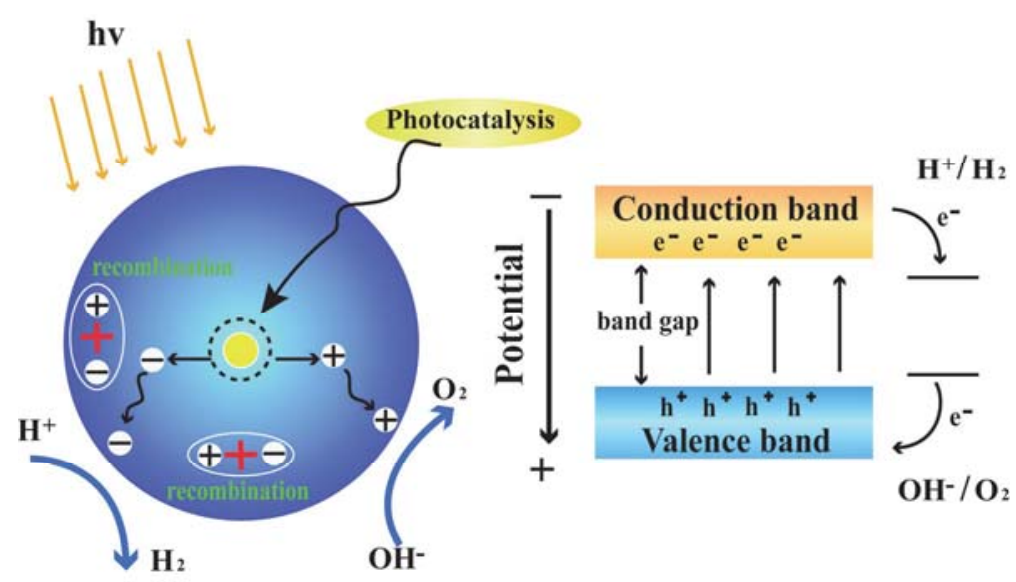

图 8 半导体光催化原理图

Figure 8 Schematic photoexcitation in a solid followed by deexcitation events 
$\mathrm{Pt} / \mathrm{CNU}-\mathrm{ATCN}$ 量子产率约为 $8.8 \%$, 在 $3 \mathrm{~h}$ 的连续照射 下, 总产氢量为 $1.55 \mathrm{mmol}$.

除了以上所报道的氮化碳外, 2014 年, Lotsch 课题 组 将 1,3,5-tris-(4-formyl-phenyl)triazine (TFPT) 和 2,5-diethoxy-terephthalohydrazide (DETH)采用腙键的连 接方式合成了具有光催化活性的 TFPT-COF(图 10a)材 料 ${ }^{[91]}$. TFPT-COF 材料为层状结构, 并层层堆垛成蜂窝 状, 其 BET 比表面积达到 $1603 \mathrm{~m}^{2} \cdot \mathrm{g}^{-1}$. TFPT-COF 材料 的孔径大小为 $3.8 \mathrm{~nm}$, 它具有良好的吸光能力, 能够吸 收 $400 \mathrm{~nm}$ 左右波长的光, 并可以延伸到 $600 \mathrm{~nm}$. 当将 金属铂催化剂载入 TFPT-COF 结构中后, 用抗坏血酸钠 作为牺牲试剂时, TFPT-COF/Pt 材料能持续有效的催化 光解水制氢反应, 产氢效率达 $230 \mu \mathrm{mol} \cdot \mathrm{g}^{-1} \cdot \mathrm{h}^{-1}$, 当改 用 $10 \%$ 的三乙醇胺 (TEOA) 作为牺牲试剂时, 产氢效率 能够达到 $1970 \mu \mathrm{mol} \cdot \mathrm{g}^{-1} \cdot \mathrm{h}^{-1}$ (图 10b).

\section{2 太阳能电池}

太阳能电池是一种将光能转化为电能的储能器件, 由于太阳能是一种取之不尽, 用之不竭的绿色能源, 在 近几十年里, 无机太阳能电池 ${ }^{[22]}$ 、有机太阳能电池 ${ }^{[93,94]}$

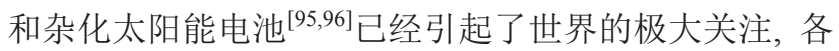
国科学家纷纷从事于太阳能的研究. 常规的杂化电池主 要是由 $\mathrm{TiO}_{2}{ }^{[97]}, \mathrm{ZnO}, \mathrm{SnO}_{2}, \mathrm{Nb}_{2} \mathrm{O}_{5}, \mathrm{In}_{2} \mathrm{O}_{3}, \mathrm{SrTiO}_{3}$, $\mathrm{Zn}_{2} \mathrm{SnO}$ 等纳米晶作为电子受体, 而贯穿在电池结构中 的聚合物充当电子供体. 晶型的 COM 材料具有较高的 比表面积、多孔性、含有 $\pi$ 共轭体系, 能够进行功能化 的修饰, 具有稳定的骨架结构, 此外, 良好的电子传输 性和半导体性质可以作为电子供体应用于太阳能电池 中.

Bein 和 Knochel 等 ${ }^{[84]}$ 采用 TTBA 和 HHTP 合成了 能够作为电子供体的噻吩基 TT-COF. TT-COF 的比表面 积为 $1810 \mathrm{~m}^{2} \cdot \mathrm{g}^{-1}$, 孔体积为 $1.19 \mathrm{~cm}^{3} \cdot \mathrm{g}^{-1}$, 孔径大小为 $3.0 \mathrm{~nm}$. TT-COF 能够与电子受体 PCBM 构成一种新的
结构有序的电子供体-受体体系. 光谱分析证实了光诱 导激发产生的电子从 TT-COF 进入到 PCBM 的多孔通道 中(图 11a). 为了研究 TT-COF:PCBM 电子供体-受体体 系的光电性能，他们设计了一块厚 $200 \mathrm{~nm}$ 的 ITO/TT-COF:PCBM/Al 三明治结构的器件, 在模拟太阳 光为 $\mathrm{AM} 1.5$ 的光照条件下测得开路电压 $622 \mathrm{mV}$, 短路 电流密度为 $0.213 \mathrm{~mA} \cdot \mathrm{cm}^{-2}$, 填充因子为 $40 \%$, 光电转 化效率为 $0.053 \%$ (图 11b). 2013 年, Jiang 等 ${ }^{[53]}$ 合成了一 种化学结构稳定, 具有开放通道、拓扑结构的二维 $\mathrm{CS}-\mathrm{COF}$ (图 11c)材料, 采用热蒸汽法, $\mathrm{C}_{60}$ 能够扩散到 $\mathrm{CS}-\mathrm{COF}$ 开放的通道里, 形成结构有序的 CS-COF $\mathrm{CC}_{60}$. 在偏压为 $1.5 \mathrm{~V}$ 下, 测得 $\mathrm{Al} / \mathrm{CS}-\mathrm{COF} \mathrm{C}_{60} / \mathrm{Au}$ 三明治结 构的太阳能电池的光电流高达 $2.0 \mu \mathrm{A}$, 暗电流 $0.029 \mathrm{pA}$. 在室温的条件下, 利用 CS-COF $\mathrm{C}_{60}$ 材料制作的薄膜太 阳能电池在光照 AM 1.5 时, 测得光电转化效率为 $0.9 \%$, 开路电压为 $0.98 \mathrm{~V}$, 短路电流密度为 $1.7 \mathrm{~mA} \cdot \mathrm{cm}^{-2}$, 填 充因子为 0.54 (图 11d). 采用类似的合成方法, 该课题组 又合成了一种高度有序, 开放通道的电子供体一受体的 异结质 $\left(\mathrm{C}_{60}\right) \mathrm{y}-\mathrm{ZnPc}-\mathrm{COFs}$ 材料 ${ }^{[98]}$, 用于太阳能电池的研 究.

尽管如此, 这些基于 $\mathrm{COM}$ 材料的太阳能电池器件, 均表现出较小的短路电流密度和较低的光电转化效率. 其原因除了材料本征光电性能外, 现报道的 COM 材料 的溶解性也是不容忽视的问题. 由于材料的不溶或难溶 性, 给材料加工成膜带来了困难, 使得难于控制膜的品 质，如：膜表面粗糙度、厚度等. 而低品质的薄膜不利于 提高器件效率, 给实际的应用带来了很大的挑战, 因此 制备可溶性的 COM 材料以及高品质 COM 膜技术是突 破此类太阳能电池的应用的关键. 此外，提高基于 $\mathrm{COM}$ 材料的太阳能电池器件的短路电流密度和光电转 化效率, 还可以从以下几方面着手: (i)向 COM 材料结构 添加吸光基团，增大 COM 材料对于太阳光的吸收范围，
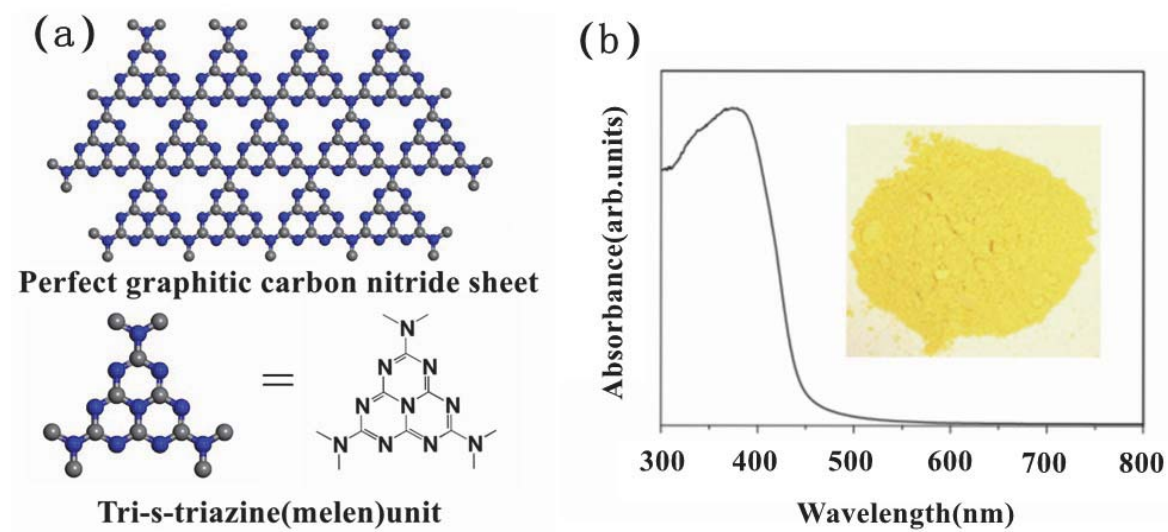

图 9 (a)石墨烯状氮化碳结构的构建原理图; (b)氮化碳紫外吸光谱图(插入图为光催化剂照片) ${ }^{[88]}$

Figure 9 (a) Schematic diagram of a perfect graphitic carbon nitride sheet constructed from melem units; (b) Ultraviolet-visible diffuse reflectance spectrum of the polymeric carbon nitride (Inset: Photograph of the photocatalyst) ${ }^{[88]}$ 
<smiles>CCOc1cc(C(N)=O)c(OCC)cc1C(N)=O</smiles>

2,5-diethoxyterephthalohydrazide (DETH)<smiles>O=Cc1ccc(-c2nc(-c3ccc(CO)cc3)nc(-c3ccc(C(F)(F)F)cc3)n2)cc1</smiles>

1,3,5-tris(4-formyl-phenyl)triazine (TFPT)

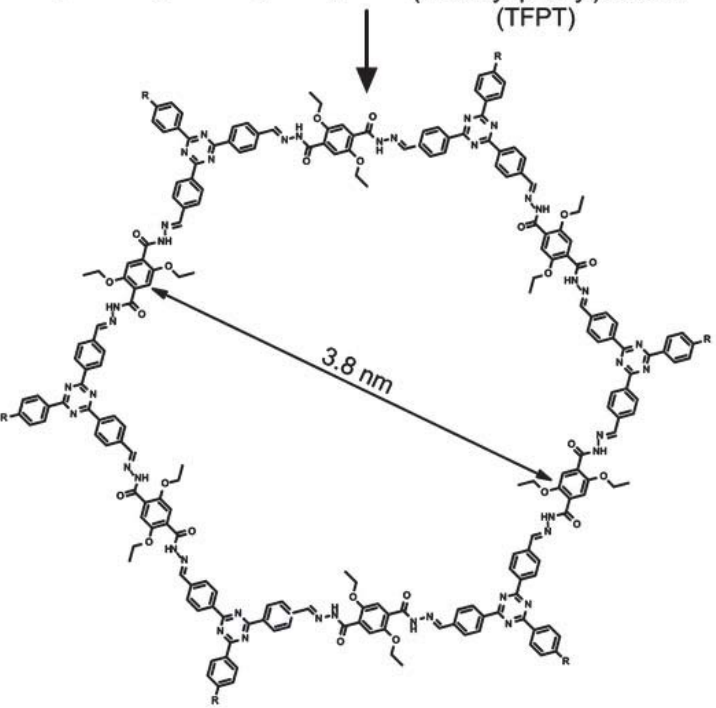

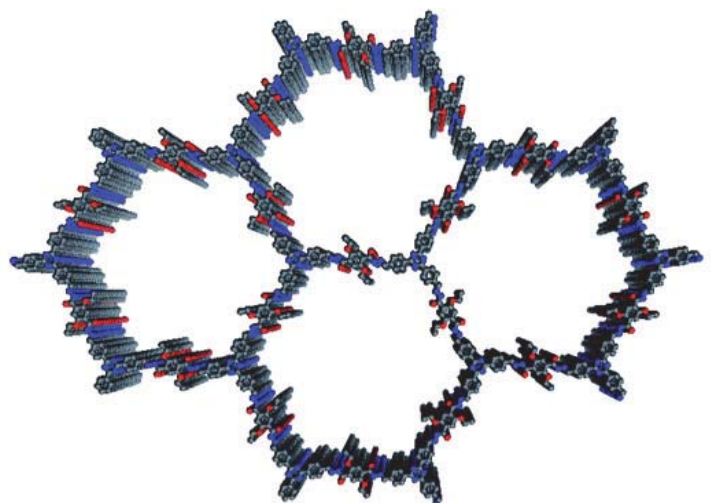

(b)

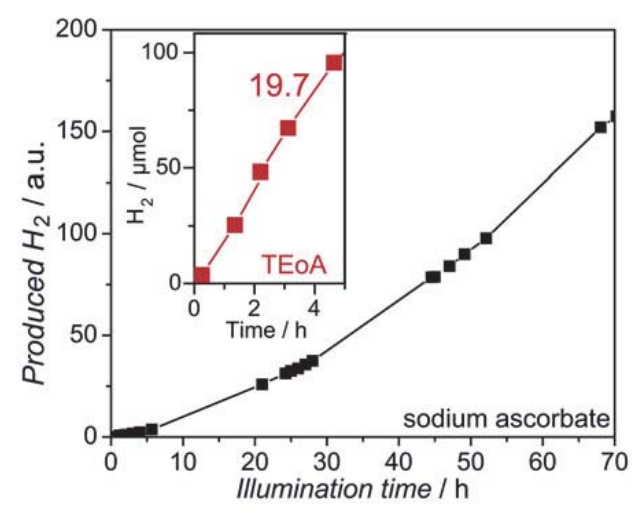

图 10 (a) TFPT-COF 合成示意图. (b)抗坏血酸钠水溶液中, Pt 负载的 TFPT-COF 在可见光 $(\lambda>420 \mathrm{~nm}$ )照射下的产氢量随照射时间的变化图. 插入 图为在 $10 \mathrm{vol} \%$ 三乙醇胺水溶液中超 $5 \mathrm{~h}$ 的析氢速率 $19.7 \mathrm{mmol} \cdot \mathrm{h}^{-1}$ (红色 $)^{[91]}$

Figure 10 (a) Scheme showing the condensation of the two monomers to form the TFPT-COFs. (b) Time course of hydrogen evolution from an aqueous sodium ascorbate solution by the Pt-modified TFPT-COF under visible light irradiation $(\lambda>420 \mathrm{~nm})$. The inset shows the hydrogen evolution rate $(19.7$ $\mathrm{mmol} \cdot \mathrm{h}^{-1}$ ) from $10 \mathrm{vol} \%$ aqueous triethanolamine solution over $5 \mathrm{~h}(\mathrm{red})^{[91]}$

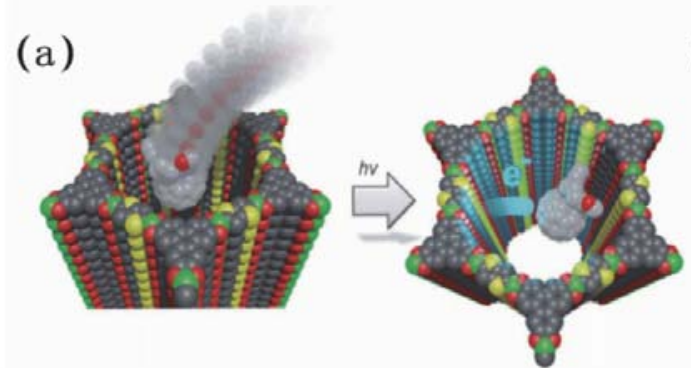

(c)

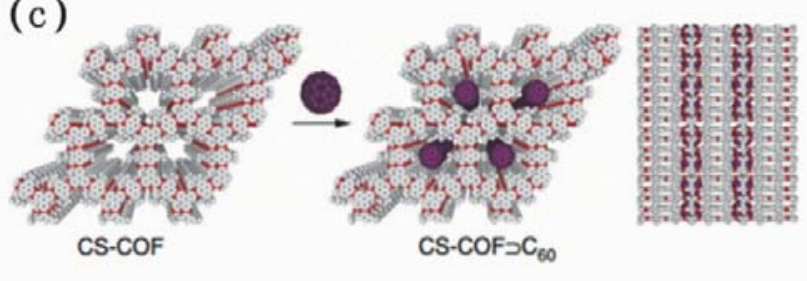

(b)

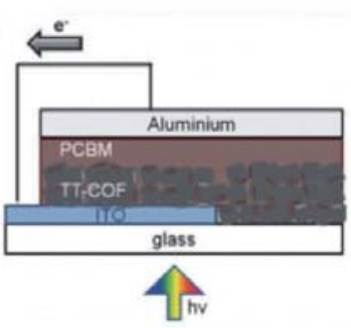

(d)

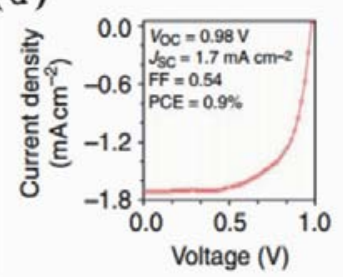

图 11 (a) TT-COF 和 PCBM 主客体络合物的分子示意图(C 灰色, B 绿色, $\mathrm{O}$ 红色, $\mathrm{S}$ 黄色, 为了能分辨清晰只展示了一个 PCBM 分子, 依照实验 中的陈述, COF 的通道存在于 PCBM 中); (b)由 TT-COF 制作的太阳能电池结构图示; (c) 升华结晶富勒烯负载到 CS-COF 一维的通道里合成 CS-COF $\mathrm{C} 60$ 的过程图示(白色: 碳; 红色: 氮; 紫色: 富勒烯)以及 CS-COF 2 C60 的侧视图; (d)太阳能电池在光照强度为 $1.5 \mathrm{AM}$ 下的 $J-V$ 曲线

Figure 11 (a) Schematic representation of the host-guest complex of TT-COF and a PCBM molecule to scale (C grey, O red, B green, and S yellow). For clarity only one PCBM molecule is shown, whereas in the experiments described, the COF channels are loaded with the PCBM phase. (b) Representation of TT-COF-based photovoltaic cell. (c) Schematic representation of synthesis of CS-COF JC60 by sublimed crystallization of fullerenes in the open one-dimensional channels (white: carbon; red: nitrogen; purple: fullerene). A side view of CS-COF 2 C60 is also shown. (d) $J$ - $V$ curve of the photovoltaic cell under irradiation with air mass 1.5 conditions 
充分利用各个波长的太阳光; (ii)对 COM 材料进行有效 的掺杂, 在成型或成膜的 COM 材料产生一些色散位点, 诱使发生光色散来增加光程从而增大电流密度; (iii)优 化电池机构, 如添加电子传输层和电子阻挡层, 能够有 效的促使激发的电子传输至外电路, 避免电子在电池内 部复合, 降低电池的效率, 也可以优化各层的厚度来降 低电池的内阻而起到提到太阳能电池光电转化效率的 目的.

\section{3 氧还原反应}

制备高效稳定的阴极氧还原反应(Oxygen Reduction Reaction: ORR)催化剂材料是突破然料电池应用技 术面临的重要挑战, 是实现清洁能源开发的关键途径. 目前大部分商用体系还是基于铂系催化剂 ${ }^{[99,100]}$, 而高 昂的价格、贵乏的铂资源, 加上较差的稳定性和对中间 产物的中毒性, 制约了燃料电池的发展, 因此发展非贵 金属或非金属催化剂具有重大的意义. 而 COM 材料为 其提供了便捷可控合成的平台, 可以利用化学的可控手 段, 定向设计裁剪出特定结构的 COP 前驱体, 再经高温 裂解，可制备丰富的新型电催化碳材料.

石墨烯作为世界上电子迁移率最高的材料, 被广泛 地用于能源转化与存储的领域. 然而, 由于石墨烯材料 缺乏良好的催化活性中心, 所以各种掺杂 (N, S, B, P 等) 方法被广泛地用来提高其氧还原性能. 由于与 $\mathrm{C}$ 原子相 邻且具有较大电负性, $\mathrm{N}$ 掺杂石墨烯研究便变得最为广 泛，因此富氮型碳材料被广泛关注. Pachfule 等以富氮 型 PAF-6(由三聚氰氯和哌嗪缩聚而成 ${ }^{[101]}$ ) 作为模板, 加 入呋喃醇作为补充碳源, 经高温裂解得到富氮碳材料 POF-C(N 的含量约 $6 \mathrm{wt} \%)$, 在 $0.1 \mathrm{~mol} / \mathrm{L}$ 碱性电解液中 起始电位比商用 $20 \% \mathrm{Pt} / \mathrm{C}$ 高约 $40 \mathrm{mV}$, 但半波电位和极 限电流依然不如 $\mathrm{Pt} / \mathrm{C}^{[102]}$. 为了更好地控制 $\mathrm{N}$ 掺杂的位 置, 我们组通过分子的科学设计, 采用含三嗪 $\mathrm{N}$, 卟啉 $\mathrm{N}$ 以及胺 $\mathrm{N}($ 图 12a)的单体, 可控合成不同含 $\mathrm{N}$ 的 COP 前驱体, 然后经过高温裂解, 制备出一系列 $\mathrm{N}$ 掺杂碳材 料(因结构类似石墨烯, 我们将这些由 COP 材料衍生的 碳材料叫做 COP 石墨烯), 来调控其电催化活性 ${ }^{[36]}$. 为 了更好地理解 $\mathrm{N}$ 掺杂对 COP 材料的电学性质的影响, 我们采用密度泛函理论计算了 4 种 COP 石墨烯材料的 电学性质. 如图 $12 \mathrm{~b}$ 所示: 巴德电荷密度显示, $\mathrm{N}$ 周围的 电荷密度较高, 说明电子主要集中在 $\mathrm{N}$ 原子周围, 而噻 吩硫原子附近的电荷密度非常低, 硫原子形成了一个断 桥, 阻碍了电子的传输. 而三嗪 $\mathrm{N}$ 的电荷密度更强, 因 此, COP-4 中电荷传输比 COP-2 中的要好, 而卟啉环中 电子由于被较长的四连苯隔断, 使得电子离域程度降 低. 因此, 理论上可推测出它们的电化学活性的顺序为: C-COP-4 $>$ C-COP-2 $>$ C-COP-P $>$ C-COP-T, 这一预测 也得到了实验的验证(图 $12 \mathrm{c}$ ). 在 $0.1 \mathrm{~mol} / \mathrm{L} \mathrm{O}$ 饱和的 $\mathrm{KOH}$ 溶液中, C-COP-4 和商用的 $\mathrm{Pt} / \mathrm{C}$ 具有相似的半波电 位, 略低的极限电流密度. 进一步的第一性原理的计算
表明，在 C-COP-4 体系中，氧气偏好于平行吸附在三嗪 $\mathrm{N}$ 邻近的芳环上, 吸附后的氧气的键长从纯氧气分子的 $1.216 \AA$ 增长到 $1.231 \AA$, 使得 $\mathrm{O}-\mathrm{O}$ 分子键减弱, 加速 氧气在 C-COP-4 电极上的还原(图 12d).

为进一步提高 $\mathrm{COM}$ 衍生碳材料的电催化活性, 我 们课题组通过卟啉环耦合非贵金属( $\mathrm{Fe} 、 \mathrm{Co}$ 和 $\mathrm{Mn}$ )的方 法, 如图 13a 所示. 由于合成出的 COP 材料较强的水热 稳定性，首先通过卟啉分子耦合非贵金属，合成不同金 属负载的 COP 单体，然后将 “订制” 的单体，可控合成 金属均匀分散二维 COP 前驱体，最后经高温裂解制备 出非贵金属掺杂的 COP 石墨烯. 如图 13b, 在碱性条件 下，较未掺杂的 COP 石墨烯，其氧还原催化活性获得极 大地提高. 在 $\mathrm{Fe} 、 \mathrm{Co} 、 \mathrm{Mn}$ 掺杂中, $\mathrm{Fe}$ 和 $\mathrm{Co}$ 掺杂效果较 好. 特别是, Co 掺杂的 COP 石墨烯催化剂表现出优于商 用 $\mathrm{Pt} / \mathrm{C}$ 催化剂的性能, 其动力学电流为商用 $20 \% \mathrm{Pt} / \mathrm{C}$ 材料的 1.4 倍. 而 Fe 掺杂的 COP 石墨烯起始电位也高 于 $\mathrm{Pt} / \mathrm{C}$, 但半波电位稍低于 $\mathrm{Pt} / \mathrm{C}$. 不仅如此, 在酸性条 件下, Fe 掺杂的 COP 石墨烯的起始电位依然优于商用 $\mathrm{Pt} / \mathrm{C}$. 在酸碱环境下, $\mathrm{Fe} / \mathrm{Co}$ 掺杂的 COP 石墨烯材料的电 子数都在 3.8 附近(图 13c), 暗示着四电子反应过程. 更 重要的是无论在酸、碱性条件下, Fe/Co 掺杂的 COP 石 墨烯催化剂均表现出良好的抗甲醇、一氧化碳中毒性和 稳定性, 展示出优异的应用前景. Feng 课题组 ${ }^{[103]}$ 也发现 了相似的提高效果. 如图 13d 所示, 他们用四苯基卟啉 钴作为单体，通过 Yamamoto 自聚，合成了金属卟啉基 的 CMP 材料, 然后经高温碳化，得到目标碳材料. 他们 的实验结果也表明, Co 掺杂的 CMP 衍生的碳材料的电 化学活性较未负载的样品得到了很大的提高. $800{ }^{\circ} \mathrm{C}$ 裂 解样品 CoP-CMP800 具有最好的电催化活性, 在 0.1 $\mathrm{mol} / \mathrm{L} \mathrm{O}_{2}$ 饱和的 $\mathrm{KOH}$ 电解液中, CoP-CMP800 的半波电 位较未负载 $\mathrm{H}_{2} \mathrm{P}-\mathrm{CMP} 800$ 提高了约 $80 \mathrm{mV}$ (图 13e), 在 $-0.4 \sim-0.3$ ( V vs. $\mathrm{Ag} / \mathrm{AgCl}$ ) 间 CoP-CMP800 的电子转 移数为 $3.83 \sim 3.86$ (图 13f), 暗示着反应为四电子反应.

除了以纯 $\mathrm{COM}$ 材料作为前驱体制备电催化材料外, 石墨烯和 COM 材料的复合材料也备受关注. 2013 年, Feng 课题组 ${ }^{[104]}$ 制备了一类 “三明治” 结构的复合材料. 如图 14a 所示: 首先对氧化石墨烯(GO)进行溴苯修饰, 然后通过含硫、氮或共掺杂的配体与溴苯修饰的 $\mathrm{GO}$, 采用 Sonogashira-Hagihara 偶联反应聚合而成 “三明 治”结构的复合材料：石墨烯基的 C M P 带 (Graphene-based conjugated microporous polymer sheets: GMPs). 在碱性条件下, 氮掺杂 GMC-N, 硫掺杂 GMC-S，以及氮硫共掺杂 GMC-NS 三种材料，具有相似 的起始电位, 而 GMC-NS 具有最高的半波电位, GMC-S 具有较高的极限电流, GMC-S 的半波电位较 $20 \% \mathrm{Pt} / \mathrm{C}$ 相差 $72 \mathrm{mV}$ (图 $14 \mathrm{~b}$ 和 $14 \mathrm{c}$ ). 该课题组通过席夫碱反应 也制备了 $\mathrm{B} / \mathrm{N}$ 共掺杂的石墨烯与 $\mathrm{COM}$ 的复合材料，经 高温裂解制得碳材料: G-CBP $(5.4 \% \mathrm{~B}, 5.3 \% \mathrm{~N})$, 然而电 

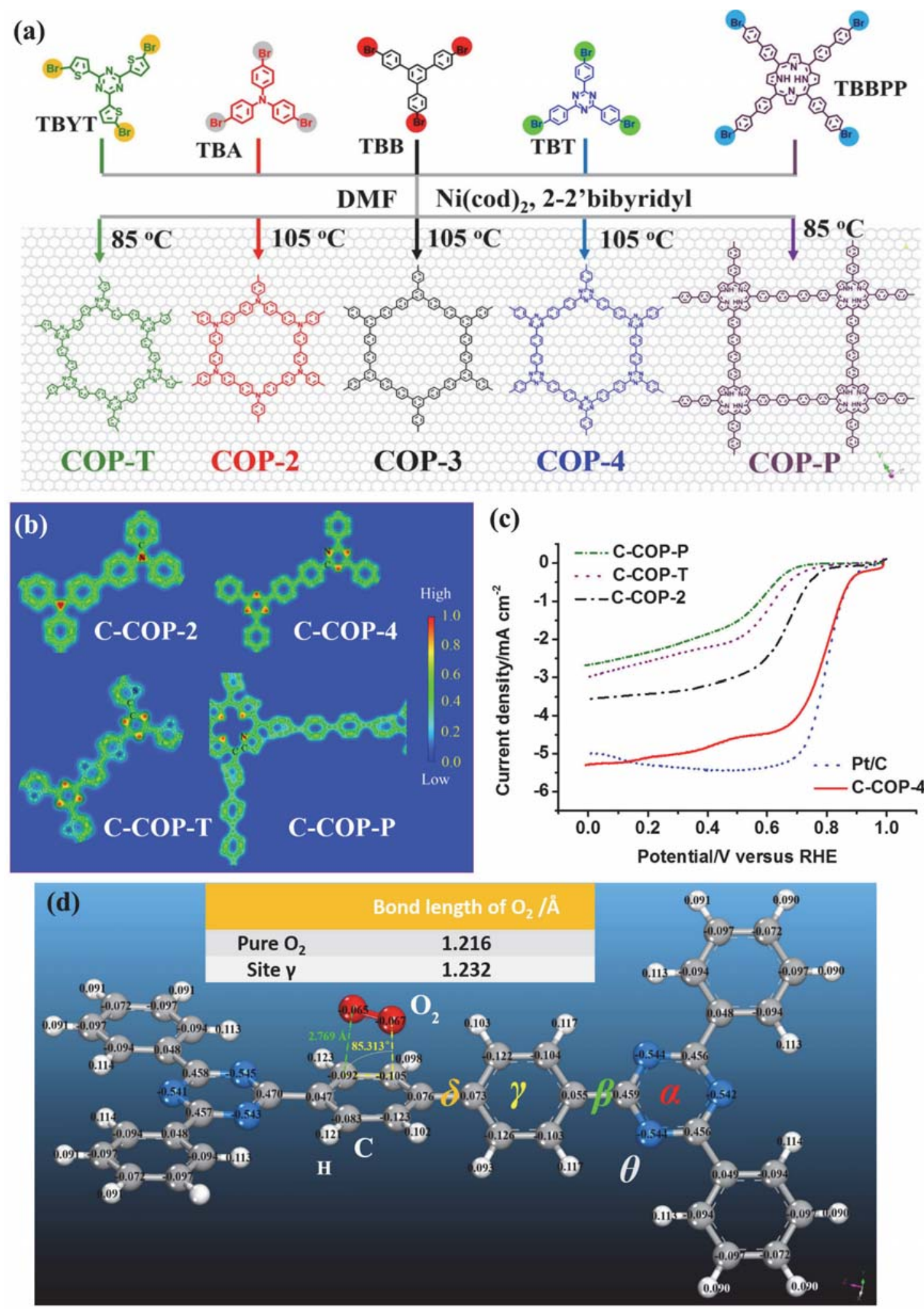

图 12 (a)不同 $\mathrm{N}$ 分布的 COP 材料的合成示意图及其分子结构; (b)四种 $\mathrm{N}$ 掺杂的 COP 石墨烯的巴德电荷密度分布; (c) N 掺杂 COP 石墨烯材料在 $0.1 \mathrm{~mol} / \mathrm{L} \mathrm{KOH}$ 溶液中的极化曲线; (d) C-COP-4 材料中的吸附氧模型, 插入的表格为纯氧和氧气在 C-COP-4 体系中的最优吸附位的键长 ${ }^{[36]}$

Figure 12 (a) Schematic diagram of synthesis of N-rich COP precursors. Schematic representation of synthesis of COP-2, COP-4, COP-T and COP-P through monomers tris(4-bromophenyl)amine (TBA), 2,4,6-tris-(4-bromo-phenyl)-[1,3,5] triazine (TBT), (4'-bromo-biphenyl-4-yl)-porphyrine (TBBPP) and 2,4,6-tris(5-bromothiophen-2-yl)-1,3,5-triazine (TBYT), respectively, using nickel-catalyzed Yamamoto-type Ullmann cross-coupling reaction. The actual structures of these statistical COPs will be more complex than those represented here. (b) Partial charge density of N-doped COP graphene. (c) LSV curves of COP graphitic electrodes in $\mathrm{O}_{2}$-saturated $0.1 \mathrm{~mol} / \mathrm{L} \mathrm{KOH}$ at $1600 \mathrm{r} / \mathrm{min}$ at a sweep rate of $5 \mathrm{mV} \cdot \mathrm{s}^{-1}$. (d) Calculated charge distributions for the cluster for optimal $\mathrm{O}_{2}$ adsorbed on the COP-4 graphitic carbon. The measured distance is presented in angstroms, and the measured angle is presented in degrees. The insert table is the optimal band length of $\mathrm{O}_{2}{ }^{[36]}$ 
(a)
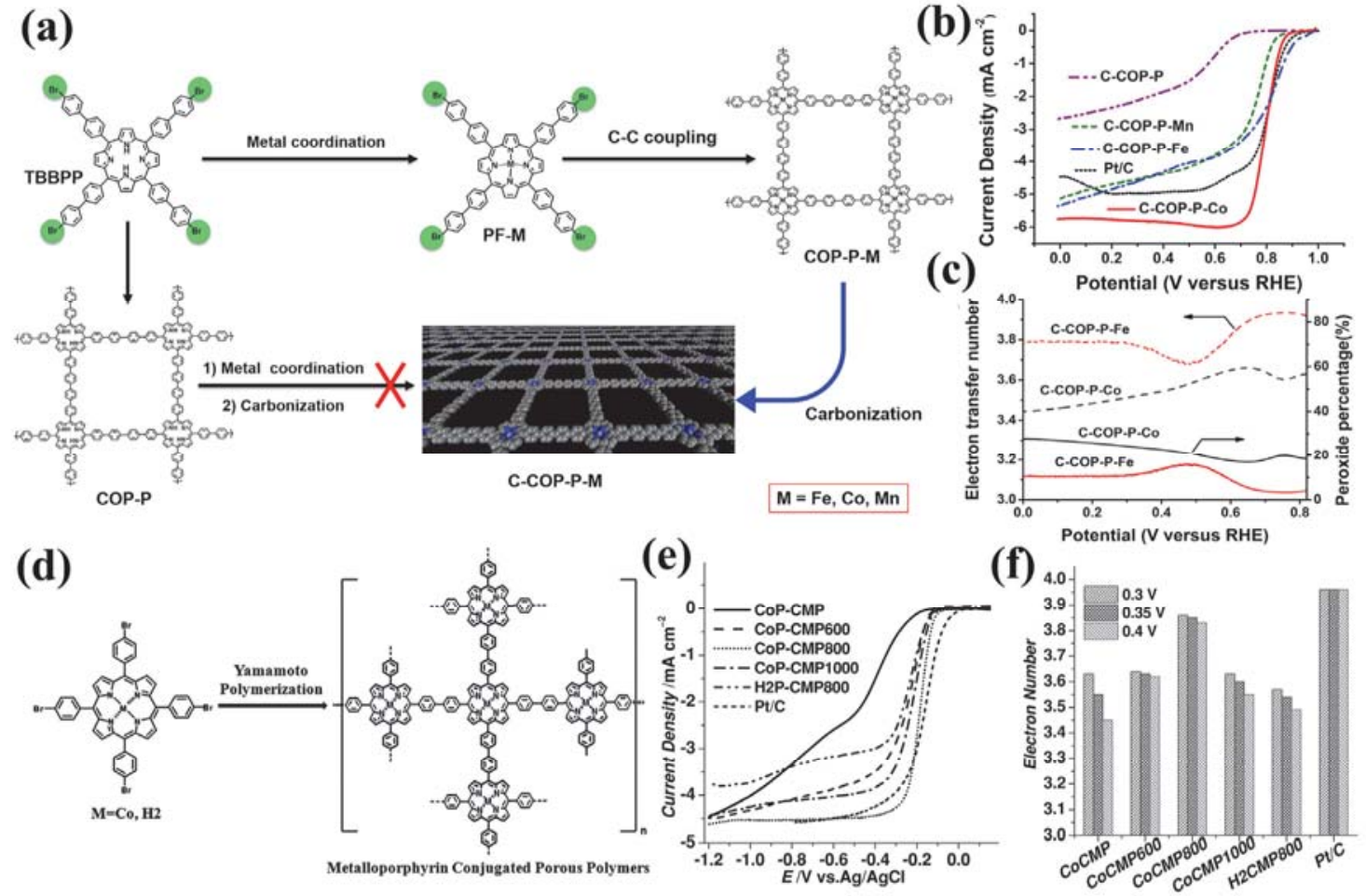

图 13 (a)非贵金属掺杂的 $\mathrm{COP}$ 石墨烯合成路线图(掺杂金属 $\mathrm{M}=\mathrm{Fe}, \mathrm{Co}$ 和 $\mathrm{Mn}$ ); (b)在 $0.1 \mathrm{~mol} / \mathrm{LM} \mathrm{O}_{2}$ 饱和的 $\mathrm{KOH}$ 溶液中非贵金属掺杂的 $\mathrm{COP}$ 的 极化曲线; (c) Fe/Co 掺杂的 COP 石墨烯的电子转移数和过氧化物的产率 ${ }^{[35]}$; (d)金属卟啉基的 CMP 材料的合成示意图; (e)在 $0.1 \mathrm{~mol} / \mathrm{L} \mathrm{O}_{2}$ 饱和的 $\mathrm{KOH}$ 溶液中金属卟啉基的 $\mathrm{CMP}$ 材料衍生碳材料的极化曲线; (f)在不同电位下 $\mathrm{CMP}$ 材料衍生碳材料的电子转移数 ${ }^{[103]}$

Figure 13 (a) Scheme for synthesis of non-precious Metal doped COP graphene. (b) LSV curves of metal-incorporated C-COP-P-M in $\mathrm{O}_{2}$-saturated 0.1 $\mathrm{mol} / \mathrm{L} \mathrm{KOH}$ at $1600 \mathrm{r} / \mathrm{min}$ at a sweep rate of $5 \mathrm{mV} \cdot \mathrm{s}^{-1}$. (c) The calculated percentage of peroxide (solid line) and the electron transfer number $(n)(\mathrm{dotted}$ line) for the metal-incorporated C-COP-P-M $(\mathrm{M}=\mathrm{Fe}, \mathrm{Co})$ samples at various potentials, derived from the corresponding RRDE data ${ }^{[35]}$. (d) Schematic representation of the chemical synthesis of metalloporphyrin-based conjugated mesoporous polymer frameworks $\left(\mathrm{M}=\mathrm{Co}, \mathrm{H}_{2}\right)(e) \mathrm{LSV}$ curves for CoP-CMP, CoP-CMP600, CoP-CMP800, CoP-CMP1000, H2P-CMP800, and Pt/C in $\mathrm{O}_{2}$-saturated $0.1 \mathrm{~mol} / \mathrm{L} \mathrm{KOH}$. (f) The $n$ values of CoP-CMP, CoP-CMP600, CoP-CMP800, CoP-CMP1000, $\mathrm{H}_{2} \mathrm{P}-\mathrm{CMP} 800$, and Pt/C against electrode potential ${ }^{[103]}$

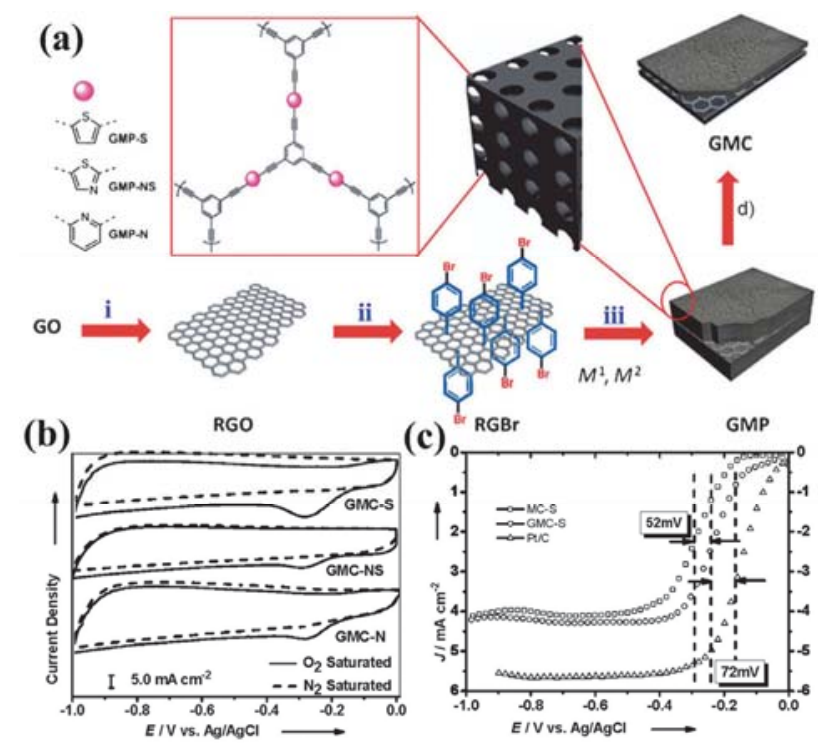

图 14 (a)石墨烯基的 $\mathrm{COM}$ 材料 $(\mathrm{GMPs})$ 和衍生碳(GMCs)的合成示意图; (b)在 $\mathrm{O}_{2}$ 和 $\mathrm{N}_{2}$ 饱和 $0.1 \mathrm{~mol} / \mathrm{L} \mathrm{KOH}$ 溶液中 $\mathrm{GMC}$ 碳的循环伏安曲线; (c)在 $0.1 \mathrm{~mol} / \mathrm{L} \mathrm{O}_{2}$ 饱和的 $\mathrm{KOH}$ 溶液中 $\mathrm{GMC}$ 碳的极化曲线 ${ }^{[104]}$

Figure 14 (a) Preparation of GMPs and related graphene-based microporous carbons (GMCs). (b) CV curves of GMCs in $\mathrm{N}_{2}$-saturated (dashed line) and $\mathrm{O}_{2}$-saturated (solid line) $0.1 \mathrm{~mol} / \mathrm{L} \mathrm{KOH}$ at a scan rate of $50 \mathrm{mV} \bullet \mathrm{s}^{-1}$; (c) LSV curves of MC-S, GMC-S, and Pt/C in $\mathrm{O}_{2}$-saturated $0.1 \mathrm{~mol} / \mathrm{L} \mathrm{KOH}$ solution at $1600 \mathrm{r} / \mathrm{min}$ at a scan rate of $5 \mathrm{mV} \cdot \mathrm{s}^{-1[104]}$ 
催化活性并不理想。在碱性条件下，半波电位较 $20 \%$ $\mathrm{Pt} / \mathrm{C}$ 低 $90 \mathrm{mV}^{[105]}$. 尽管如此, 这些复合材料衍生碳材料 的电催化稳定性和抗毒性均强于 $20 \% \mathrm{Pt} / \mathrm{C}$, 给非金属催 化剂的制备依然提供了新的方案.

\section{4 储能}

\subsection{1 锂电池}

在这过去的二十多年里, 锂离子电池与镍镉、镍锰 电池相比, 已经取得了巨大的进步和发展, 然而在其发 展过程中也遇到一些瓶颈 ${ }^{[106]}$. 首先, 对于传统的锂离 子电池阴极材料, 如 $\mathrm{LiCoO}_{2} 、 \mathrm{LiFePO}_{4}$ 等, 在理论上已 经很难再提升锂离子电池的电流密度; 其次, 在锂离子 电池大规模的工业应用的同时, 需要消耗大量的金属材 料, 比如 $\mathrm{Mn}, \mathrm{Fe}, \mathrm{Co}, \mathrm{Ni}$ 等, 这也会引起资源和环境污染 等问题. 因此, 寻找替代现有锂离子电池阴极材料仍有 重要意义.

2014 年, Jiang 等 ${ }^{[107]}$ 报道了一种能够快速充放电的 有机共价多孔聚合材料 HATN-CMP(图 15). HATNCMP 具有较高的比表面积, 交联的结构骨架, 内置了氧 化还原单元, 分层级的纳米孔道, 这些特性促进了能量 充放电中的电化学进程. 采用 HATN-CMP 材料制作的 锂电池, 通过多次循环充放电测试可知, 当电流密度为 $200 \mathrm{~mA} \cdot \mathrm{g}^{-1}$, 电池的电容量为 $100 \mathrm{mAh} \cdot \mathrm{g}^{-1}$; 电流密度 增加到 $500 \mathrm{~mA} \cdot \mathrm{g}^{-1}$, 电池的电容量为 $65 \mathrm{mAh} \cdot \mathrm{g}^{-1}$; 随着 电流密度增加到 $800 \sim 1000 \mathrm{~mA} \cdot \mathrm{g}^{-1}$, 电池的电容量稳定 在 $50 \mathrm{mAh} \cdot \mathrm{g}^{-1}$. 结果表明 HATN-CMP 是一种绿色良好 的电极材料运用于高能存储的器件中.

同年, Feng 课题组 ${ }^{[57]}$ 报道了采用二维石墨烯和多孔
的聚芳基三嗪衍生物合成的一种共价多孔 G-PPFs 材料 作为锂离子电池的阴极材料. G-PPFs 呈现出多孔的纳米 片状结构, 高的比表面积 $\left(651 \sim 1683 \mathrm{~m}^{2} \cdot \mathrm{g}^{-1}\right)$, 石墨和聚 芳基三嗪衍生物耦合具有很强的电化学活性, 用 G-PPFs 材料作为锂离子电池的阴极材料具有较好的稳 定性, 当电流密度为 $5 \mathrm{~A} \cdot \mathrm{g}^{-1}$, 循环测试 5100 次, 电池的 电容量稳定在 $395 \mathrm{mAh} \cdot \mathrm{g}^{-1}$; 随着电流密度为 $15 \mathrm{~A} \cdot \mathrm{g}^{-1}$, 电池的电容量稳定在 $135 \mathrm{mAh} \cdot \mathrm{g}^{-1}$. 此外, Feng 课题 组 ${ }^{[108]}$ 还设计了一种大孔结构锂电池的阴极材料, 即 MGTF 材料 (Macroporous graphene/ $\mathrm{SnO}_{2}$ frameworks: MGTF). 他们采用二维的 $\mathrm{GO} / \mathrm{SnO}_{2}$ 纳米片作为构筑单 元，两亲聚合物聚乙烯醇(PVA)、Pluronic $(F 127$ (F127)、 聚乙烯亚胺(PEI)作为交联剂, 合成 MGTFs, 其过程如 图 $16 \mathrm{a}$ 所示. 其中合成的 $\mathrm{MGTF}_{\mathrm{PEI}}$ 锂电阴极材料表现出 优良的性能, 在电流密度为 $0.1 \mathrm{~A} \cdot \mathrm{g}^{-1}$ 时, 循环测试 120 次, 电池的电容量仍然高达 $1227 \mathrm{mAh}^{-1} \mathrm{~g}^{-1}$ (图 16c); 随 着电流密度升至 $8 \mathrm{~A} \cdot \mathrm{g}^{-1}$, 电池的电容量稳定在 273 $\mathrm{mAh} \cdot \mathrm{g}^{-1}$.

Yang 和 Lee 等 ${ }^{[109]}$ 报道了一种处于菲醌 (phenanthrenequinone: PQ)蒸汽压条件下, 借助于 $\pi-\pi$ 作 用力将菲醌束缚于有序结构的介孔碳材料 (ordered mesoporous carbon: CMK-3)的 PQ/CMK-3 锂电阴极材 料. PQ 紧束缚于 $\mathrm{CMK}-3$ 中能够缓解 $\mathrm{PQ}$ 在质子电解液 中扩散和溶解过程, 且能够增强阴极材料的导电性, 从 而提高锂电的循环充放电性能. 当电流密度为 $25.7 \mathrm{~A}$ • $\mathrm{g}^{-1}$ (电量为 $0.1 \mathrm{C}$ ) 时, 测得电池的电容量约 $220 \mathrm{mAh}$ • $\mathrm{g}^{-1}$, 循环测试 50 次, 电池容量稳定在原电容的 $89 \%$.
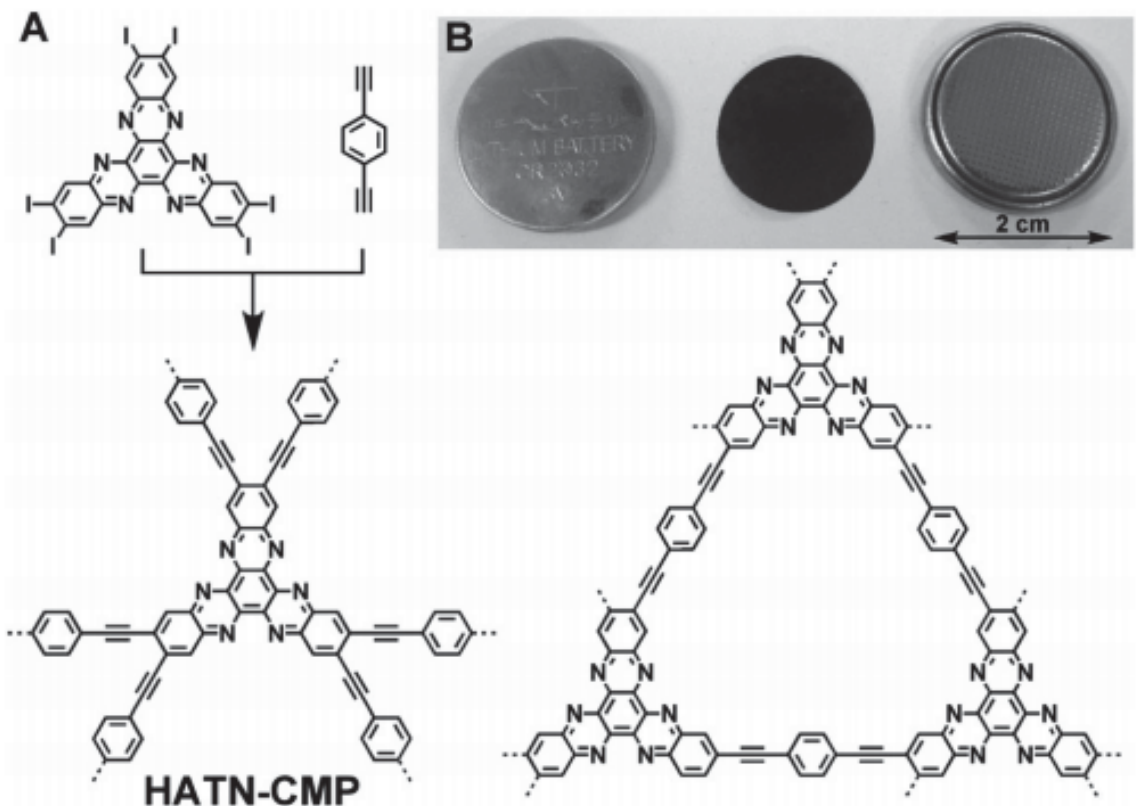

图 15 (a) HATN-CMP 的合成过程图示和由 HATN-CMP 构建的骨架图示; (b) HATN-CMP 作为电极材料及组装成的锂硫电池图片[107] Figure 15 (a) Schematic representation of the synthesis of HATN-CMP and the elementary pore structure. (b) The photos of HATN-CMP electrodes and lithium batteries thus fabricated ${ }^{[107]}$ 
(a)

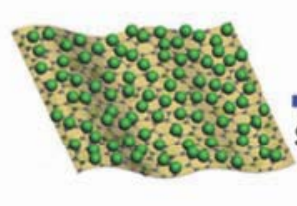

GOT

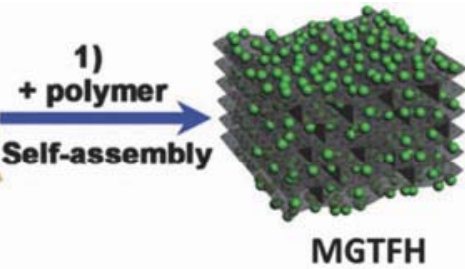

MGTFH

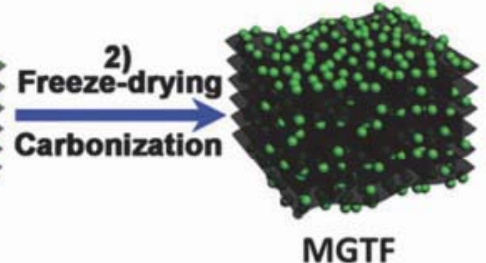

MGTF

Polymer:<smiles>OCCOCC(COCCO)OCCO</smiles>

F127<smiles>CCN(CC)CCNCCN1CCN(CCN)CC1CN(CCN)CCN(CCN)CCN</smiles>

PEI

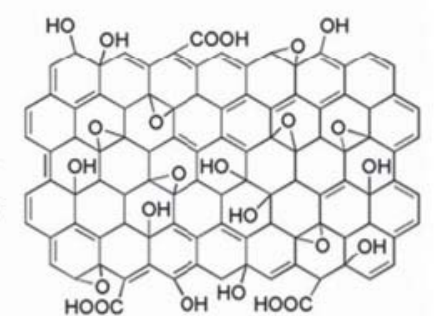

(b)

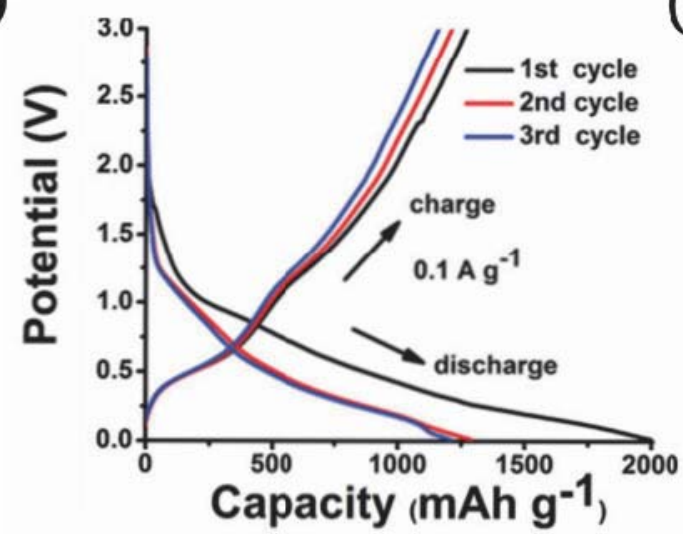

(c)

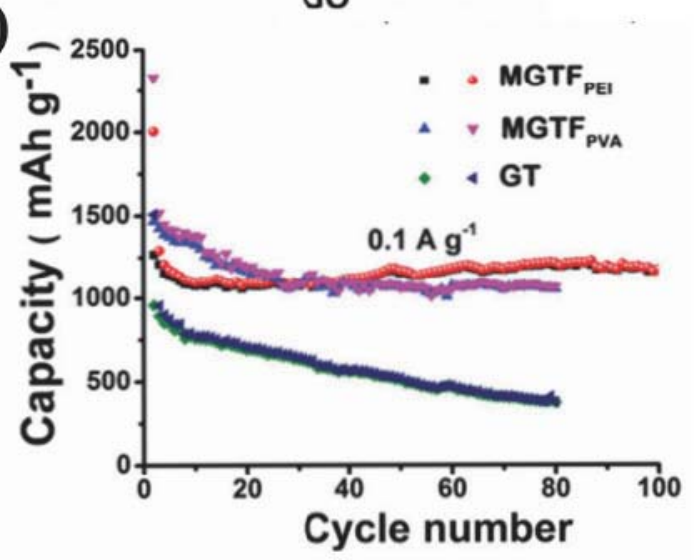

图 16 (a)杂交化 MGTF 的合成过程图示: (1)两亲聚合物水热作用下促使 GOT 进入 3 维结构凝胶状的 MGTF (MGTFH); (2) MGTF 的冷冻干燥和 压缩; (b) MGTF PEI 在电流密度为 $0.1 \mathrm{~mA} \cdot \mathrm{g}^{-1}$ 时的充/放电曲线; (c) MGTF PEI, MGTF PVA 和 GT 在电流密度为 $0.1 \mathrm{~A} \cdot \mathrm{g}^{-1}$ 时的循环性能曲线 ${ }^{[108]}$ Figure 16 (a) Schematic illustration of synthesis procedure towards MGTF hybrids: (1) assembly of GOT into 3D architectures MGTF hydrogel (MGTFH) by hydrothermal process, which is promoted by the presence of amphiphilic polymer; (2) freeze-drying and carbonization of MGTF. (b) charge/discharge profiles of MGTF PEI at a current density of $0.1 \mathrm{~mA} \cdot \mathrm{g}^{-1}$. (c) the cycle performance of MGTF PEI, MGTF PVA and GT at a current density of $0.1 \mathrm{~A} \cdot \mathrm{g}^{-1[108]}$

总之, 借助于结构有序的多孔碳材料以及其 $\mathrm{COM}$ 材料有望设计出一些用于替代金属类的锂电电极材料, 避免环境污染和资源问题, 表现出潜在的研究价值和发 展前景.

\subsection{2 锂硫电池}

锂硫电池因其较高的电流密度, 被作为高效的储能 原件广泛研究. 然而根据单位质量的单质硫完全变为 $S^{2-}$ 所能提供的电量可得出硫的理论放电质量比容量为 $1675 \mathrm{mAh} \cdot \mathrm{g}^{-1}$, 同理可得出单质锂的理论放电质量比容 量为 $3860 \mathrm{mAh} \cdot \mathrm{g}^{-1}$. 锂硫电池的理论放电电压为 2.287 $\mathrm{V}$, 当硫与锂完全反应生成硫化锂 $\left(\mathrm{Li}_{2} \mathrm{~S}\right)$ 时, 相应锂硫电 池的理论放电质量比能量为 $2600 \mathrm{Wh} \cdot \mathrm{kg}^{-1}$. 在过去的几 十年里, 由于锂硫电池较大的理论放电质量比容量和放 电质量比能量, 已经吸引了许多科学家在锂硫电池的研 究 ${ }^{[56,110 \sim 112]}$. 然而, 当前也存在很多挑战和困难, 阻碍 锂硫电池的发展和广泛应用 ${ }^{[113,114]}$. 可简要总结为以下 三个主要问题: (1)硫导电性非常差, 不利于电池的高倍
率性能; (2)大多聚硫化合物溶于电解液; (3)硫在充放电 过程中, 体积的扩大、缩小程度非常大，可能会导致电 池损坏. 为了解决硫本身不导电的问题, 通常可以采用 将硫分散到导电的媒介中, 如: 多孔碳、导电聚合物、 或者添加导体等方法. 对于电解液方面, 主要用醚类的 电解液作为电池的电解液, 电解液中加入一些添加剂, 可以有效地缓解聚硫化合物的溶解问题. 对于重复充放 电体积膨胀的问题, 可以通过改进正极材料, 主要是把 硫和碳材料复合, 或者把硫和有机物复合, 且可同时解 决硫的不导电和体积膨胀难题.

利用 COM 材料的规则结构和多孔性, 将硫针定在 $\mathrm{COM}$ 材料的纳米孔中, 阻止聚硫化合物的溶解, 提高 电池的稳定性. 2013 年, Guo 和 Dai 等 ${ }^{[55]}$ 采用多孔芳环骨 架材料 PAF 作为主体材料, 与硫混合形成锂硫电池的 阴极多孔材料 PAF-S 作为锂硫电池的阴极材料. PAF-S 在 $1.0 \mathrm{~mol} / \mathrm{L} \mathrm{LiPF}$ - $\mathrm{MiPS}$ 的电解液中和 $0.5 \mathrm{~mol} / \mathrm{L}$ LiTFSI-MPPY·TFSI 的离子液中电解液中表现出稳定性 
和电容性. 在 50 次的电池循环测试后, PAF-S 作阴极材 料的器件的电容量为 $690 \mathrm{mAh} \cdot \mathrm{g}^{-1}$, 这个容量值为最初 电池电容量值的 $83 \%$ (图 17a). 此外, 在 $25{ }^{\circ} \mathrm{C}$ 时, 1.0 $\mathrm{mol} / \mathrm{L} \mathrm{LiPF} \mathrm{LiPS}_{6}$ 的电解液中, PAF-S 作阴极材料的锂 硫电池表现出优异的稳定性(图 17b). 实验结果表明: 负载了具有多孔结构的 PAF-S 材料制作的锂硫电池, 能 有效的解决锂硫电池多次循环次数变差的问题, 且能保 证电池的稳定性. 2014 年 Liao 等 ${ }^{[115]}$ 采用结构更规则的 三嗪基材料: CTF-1, 作为硫的主体材料, 制备锂硫电池 阴极材料 CTF-S, 也使得电池稳定性提高了很多, 倍率 性能也较好. 在不同电流密度下表现出良好的可逆容 量, 即使在高电流 $1 \mathrm{C}$ 的条件下, 阴极材料依然可以传 输 $514 \mathrm{mAh} \cdot \mathrm{g}^{-1}$ 的电容. 当电流密度回到了 $0.1 \mathrm{C}$ 以后, 起始的 $750 \mathrm{mAh} \cdot \mathrm{g}^{-1}$ 的电容仍可恢复.

因此, COM 材料规则的结构可为硫的传输提供良 好的通道, 可调的纳微孔可以很好地固定硫, 有效避免 聚硫中间产物的溶解问题, 在锂硫电池领域展示出良好 的应用前景.

\subsection{3 超级电容器}

超级电容器是一种介于电容器和电池之间的储能 器件, 它既具有电容器可以快速充放电的特点, 又具有 电池的储能特性. 此外还具有功率密度大、循环稳定性 好、体积小、环境友好等特点, 得到了广泛应用 ${ }^{[116]}$. 高 比表面的碳材料(比如活性炭) 常被用作超级电容器电极 材料. 但是其孔径分布过宽和结构无序特点, 导致电解 质很难进入微孔内, 孔内的离子传递效率低. 因此超级 电容器电极材料的发展方向之一是寻找含有有序的相 互连通的孔隙结构、高比表面积、导电性好的碳材料. 如 上所述, COM 材料只含一些轻质元素, 且 $\mathrm{C}$ 含量非常 高, 具有高多孔性, 为良好的前驱体或者模板制备碳材

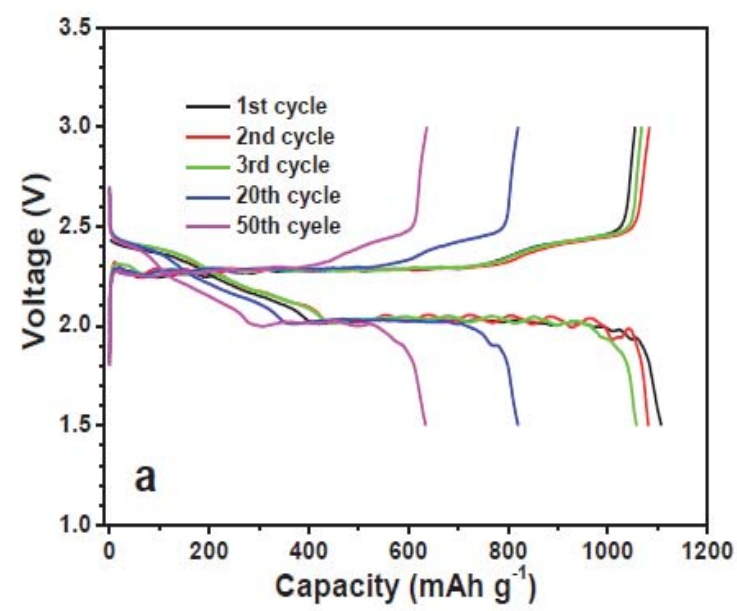

料, 再经高温裂解得到目标电极材料.

2008 年, Müllen 课题组 ${ }^{[17]}$ 以共轭多微孔高分子为 碳前驱体直接炦烧制备多孔碳. 用刚性树枝状亚苯基低 聚糖 1,3,5 反式 2'二苯并苯(oligophenylene 1,3,5-tris-2'biphenylbenzene) 做富碳单元, 通过 Hagihara-Sonogashira 耦合反应构造共轭高分子网络, 得到一维管状或 纤维状多微孔聚合物. 亚苯基低聚糖单体的聚合取向决 定了最终产物的形态. 在氩气气氛下热解, 碳化得多微 孔碳纳米管和碳纳米纤维. 这种一步合成方法简单, 不 需要模板. 得到的碳材料比表面积高达 $900 \mathrm{~m}^{2} \cdot \mathrm{g}^{-1}$, 用 作超级电容器电极材料时质量比电容达 $115 \mathrm{~F} \cdot \mathrm{g}^{-1}$. 同 年, 该课题组以阳极氧化铝(简称 $\mathrm{AAO}$, 平均孔径为 200 $\mathrm{nm}$, 孔长 $60 \mu \mathrm{m}$ ) 为模板, 在 $250{ }^{\circ} \mathrm{C}$ 热引发狄尔斯-阿尔 德交联反应制备烷基取代超支化聚亚苯基(图 18), 然后 在高温下热解, 除去模板后得到一维多介孔纳米碳 ${ }^{[118]}$. 氮气吸附脱附测试表明产物中含有大量的介孔. 热解温 度为 $800{ }^{\circ} \mathrm{C}$ 时的产物比表面积为 $1140 \mathrm{~m}^{2} \cdot \mathrm{g}^{-1}$. 电压扫 描速率为 $5 \mathrm{mV} \cdot \mathrm{s}^{-1}$ 时比电容为 $304 \mathrm{~F} \cdot \mathrm{g}^{-1}$, 远高于普通 的多孔碳材料 ${ }^{[88,119]}$. 经过 1000 次循环后比电容保持在 $298 \mathrm{~F} \bullet \mathrm{g}^{-1}$.

研究表明, 在碳材料中掺入杂原子能够提高材料的 电容性能 ${ }^{[120,121]}$. 通过采用富氮的 COM 材料做前驱体 碳化可以得到含氮的多孔碳材料, 还可用不同的单体修 饰或聚合调整，在分子水平控制最终碳材料的化学成分 和形态结构. Xiang 等 ${ }^{[122]}$ 采用高比表面积的 PAF-1 ${ }^{[29]}$ 作 为前驱体，利用氨气对其进行氮掺杂，得到三维结构掺 氮的多孔 N-PAF-Carbon 材料(图 19a). 与没有掺氮的 PAF-Carbon 材料相比, 其导电性和充放电电流得到了 明显提高(图 19b f f). 未掺 $\mathrm{N}$ 的 PAF-carbon 材料的电容 性质与 $\mathrm{Li}$ 等报道的结果类似 ${ }^{[123]}$. 在 $0.2 \mathrm{~A} \cdot \mathrm{g}^{-1}$ 下的电流

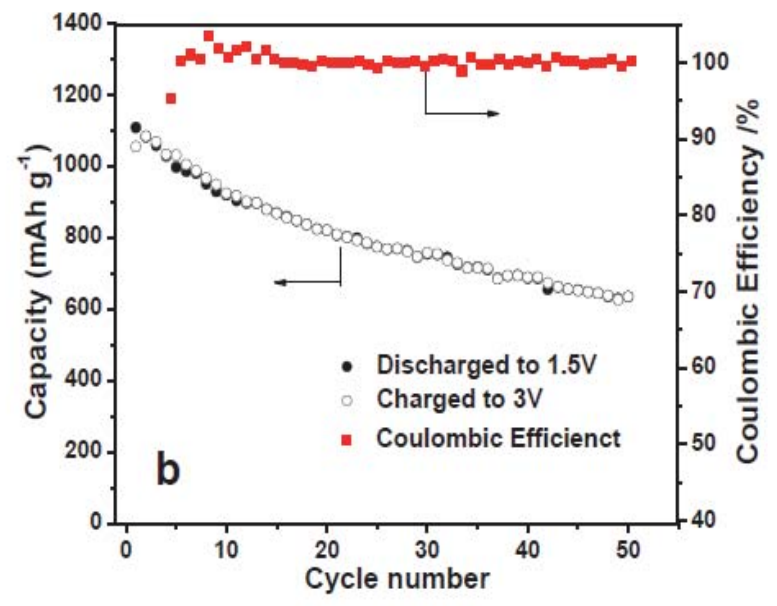

图 17 (a) Li||PAF-S 锂硫电池恒电流放电/充电曲线; (b) $25{ }^{\circ} \mathrm{C}$ 时, $\mathrm{Li} \| \mathrm{PAF}-\mathrm{S}$ 锂硫电池以 $0.05 \mathrm{C}$ 的电流速率在 $1 \mathrm{~mol} / \mathrm{L}$ LiPF $/ \mathrm{MiPS}$ 的电解液中的循 环性能曲线 ${ }^{[5]}$

Figure 17 Galvanostatic discharge/charge curves (a) and cycling performance (b) of the Li||PAF-S cell under a current rate of $0.05 \mathrm{C}$ in $1 \mathrm{~mol} / \mathrm{L}$ $\mathrm{LiPF}_{6} / \mathrm{MiPS}$ at $25{ }^{\circ} \mathrm{C}^{[55]}$ 


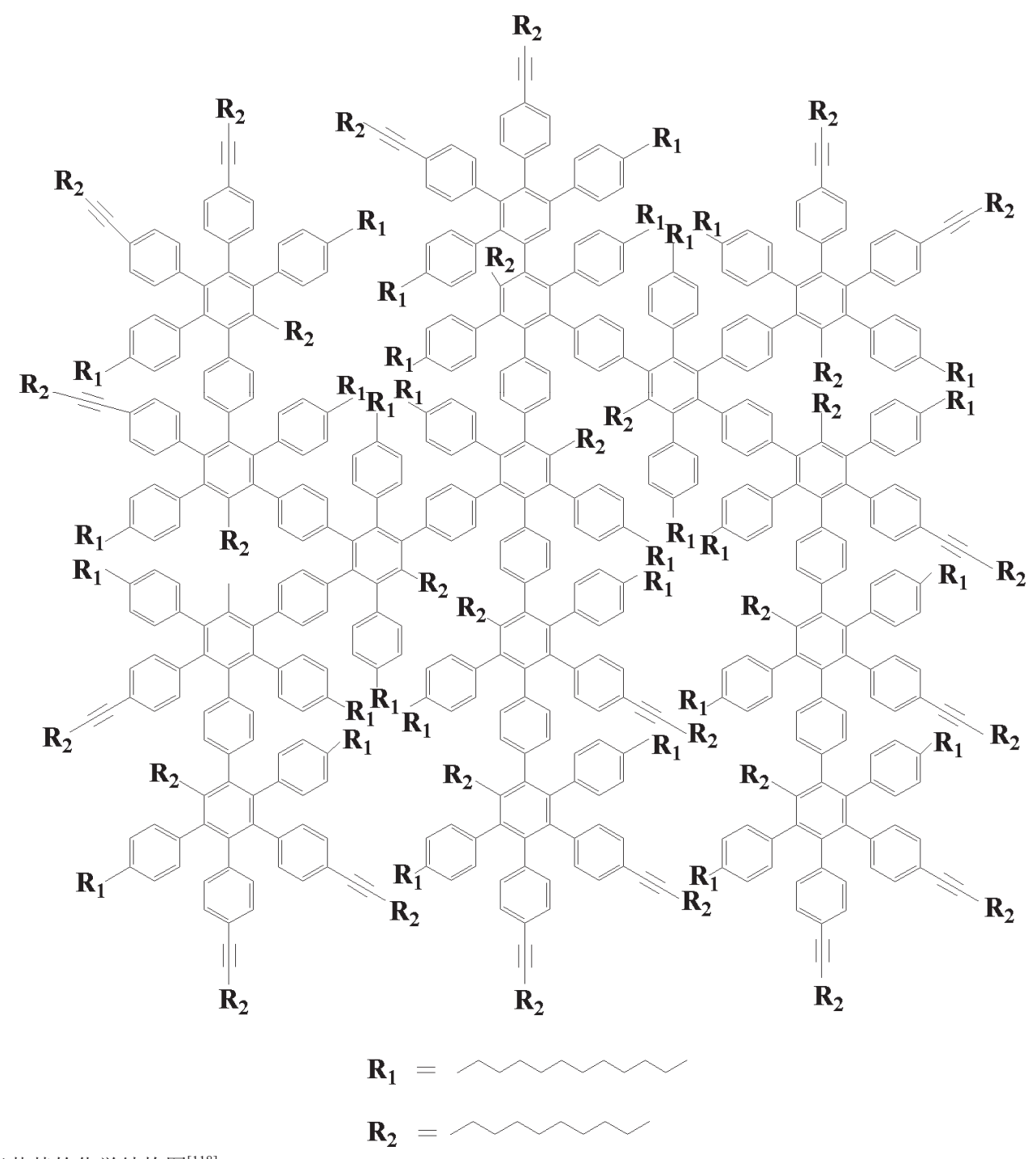

图 18 超支化聚亚苯基的化学结构图 ${ }^{[118]}$

Figure 18 Chemical structure of hyperbranched polyphenylene ${ }^{[118]}$

密度下，未经 $\mathrm{N}$ 掺杂 PAF-carbon 的充放电曲线，便表现 出明显不对称, 而经 $\mathrm{N}$ 掺杂的样品仍保持完美的充放电 对称性. 阻抗测试结果, N-PAF-Carbon 器件电阻仅为 $0.96 \Omega$, 仅为未掺杂样品器件阻抗的一半(图 $19 \mathrm{~g}$ ). 经过 9000 次的充放电, N-PAF-Carbon 材料仍保持较高的比 电容 $385 \mathrm{~F} \bullet \mathrm{g}^{-1}$, 且几乎没有损失(图 19h), 表现出了很 好的稳定性.

通过合理的选择前驱体和合成方法可以制备不同 孔径和结构形态的多孔有机材料, 还可以在孔表面引入 不同的官能团, 从而实现增强材料某方面性能的目的. Liu 等 ${ }^{[124]}$ 报道了一种制备中空球状富氮多孔碳壳的方 法, 其过程如图 20 所示. 通过在不同温度下氮气保护中 直接碳化结构可控的 COF-LZU1, 得到的碳材料 (记为 NPC-X, X 为碳化温度)BET 比表面积在 357 525 $\mathrm{m}^{2}$ • $\mathrm{g}^{-1}$ 范围, 在 $1 \mathrm{~mol} / \mathrm{L}$ 的 $\mathrm{KOH}$ 溶液中进行循环伏安测试, 电流密度为 0.5 和 $3 \mathrm{~A} \cdot \mathrm{g}^{-1}$ 时比电容分别为 230 和 190 $\mathrm{F} \cdot \mathrm{g}^{-1}$; 循环 1500 次以后电容为初始电容的 $98 \%$, 保持
良好的循环稳定性. Feng 课题组 ${ }^{[125]}$ 通过耦合石墨烯, 合 成了一种可以量产富氮的二维多孔聚合材料 TPC, 在 $800{ }^{\circ} \mathrm{C}$ 氮气保护下热解得到的 $\mathrm{TPC}-1$ 材料, 氮含量达 $8.8 \%$, 在 $6 \mathrm{~mol} / \mathrm{L}$ 的 $\mathrm{KOH}$ 溶液中进行循环伏安测试, 电 流密度为 $0.1 \mathrm{~A} \cdot \mathrm{g}^{-1}$ 时电容量高达 $424 \mathrm{~F} \cdot \mathrm{g}^{-1}$, 这个数值 远远大于希夫碱没有复合石墨烯的超级电容器材料和 目前报道石墨烯掺氮所得到的电容器材料. 另外, Feng 和 Mai 等 ${ }^{[126]}$ 通过一种巧妙而有效的方法合成了一种三 维结构的石墨烯偶合希夫碱的多孔聚合物 GS-HPPs. 采 用三聚氰胺高分子聚合物和 1,4-苯二醛生成希夫碱多孔 聚合物偶合在汽溶三维石墨烯多孔结构中. GS-HPP 材 料含有大孔、介孔、微孔，可以形成高达 $776 \mathrm{~m}^{2} \cdot \mathrm{g}^{-1}$ 的 比表面积, 在 $800{ }^{\circ} \mathrm{C}$ 氮气保护下热解, 形成了稳定、富 氮、孔道层级有序的结构. 在 $6 \mathrm{~mol} / \mathrm{L} \mathrm{KOH}$ 溶液中进行 循环伏安测试，电流密度为 $0.1 \mathrm{~A} \cdot \mathrm{g}^{-1}$ 时电容量高达 335 $\mathrm{F} \cdot \mathrm{g}^{-1}$, 在 10000 次的循环测试中, 电容量几乎没有损失, 是一种性能良好的超级电容器材料. 

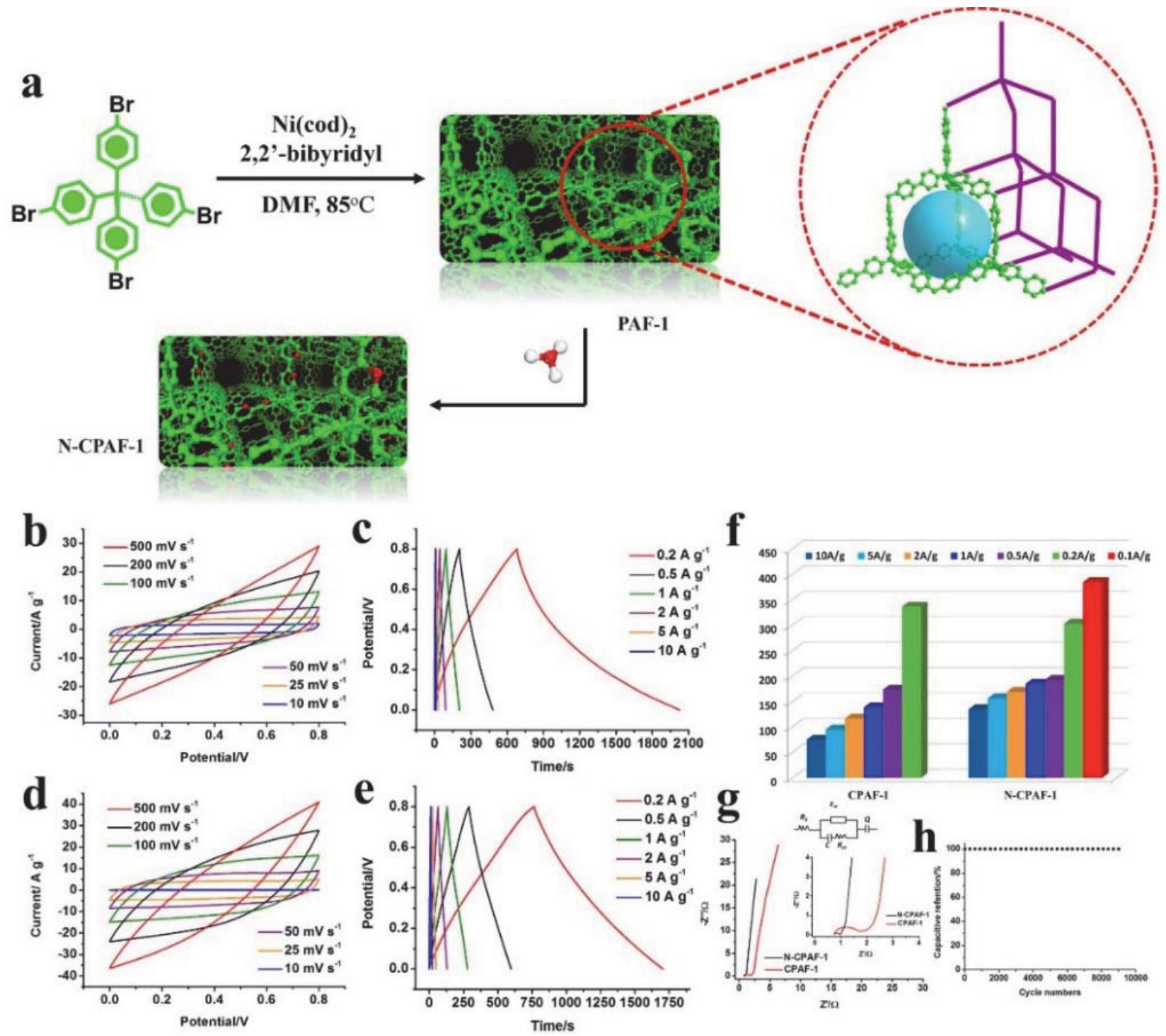

图 19 (a) $\mathrm{N}$ 掺杂 PAF-Carbon 合成示意图; (b), (d)分别为在不同扫描速率下未掺杂和 $\mathrm{N}$ 掺杂的 PAF-Carbon 材料的 CV 曲线; (c), (e)分别为不同电 流密度下未掺杂和 N 掺杂的 PAF-Carbon 材料的充放电曲线; (f) 不同电流密度下的电容值; (g) 未掺杂和 N 掺杂的 PAF-Carbon 材料的 Nyquist 图, 插 入图为等效电路和高中频率下的阻抗谱图. (h)在 $5 \mathrm{~A} \cdot \mathrm{g}^{-1}$ 的电流密度下, 9000 次充放电过程的电容百分比 ${ }^{[122]}$

Figure 19 (a) The scheme for synthesis of PAF-1 materials. The cyan sphere in the right structure refers to the pore in PAF-1 and the purple lines refer to the framework of diamond structure. The actual structures of the statistical PAF-1 materials will be more complex than represented. (b) and (d) CV curves for CPAF-1 and N-CPAF-1 at scan rates of 10, 25, 50, 100, 200 and $500 \mathrm{mV} \cdot \mathrm{s}^{-1}$. (c) and (e), Charge-discharge profiles for CPAF-1 and N-CPAF-1 at current densities of $10,5,2,1,0.5$, and $0.2 \mathrm{~A}^{-} \mathrm{g}^{-1}$, respectively. (f) Specific capacitance of CPAF-1 and N-CPAF-1 at different current densities. (g) Nyquist plots of CPAF-1 and N-CPAF-1. Inset shows the impedance in the high and medium-frequency regions and an equivalent circuit as electrode materials is also inserted. (h) Capacitance percentage of N-CPAF-1 for a 9000-cycle charge-discharge test at a current density of $5 \mathrm{~A} \cdot \mathrm{g}^{-1[122]}$

改变前驱体的种类和合成的工艺可以控制最终产 物的结构形态和成分组成, 从而提高材料的性能. Jiang 课题组 ${ }^{[127]}$ 采用离子热方法合成的氮杂 $\pi$-多微孔聚合物 (简称 Aza-CMP@X, X 为温度), 它们具有以下特点: (1) 框架具有导电性; (2)骨架中的含氮单元能与电解质阳离 子和孔壁上积累的质子发生偶极相互作用; (3)微孔孔径 得到优化, 有利于充放电过程中离子的快速传递; (4) 比 表面积大, 为孔内静电分离层的形成提供大的界面. Aza-CMP 作电极材料其电容性能远超过其他的含氮多 孔碳材 料 ${ }^{[128]}$. 在电流密度为 $0.1 \mathrm{~A} \cdot \mathrm{g}^{-1}$ 下,
Aza-CMP@450 电极材料的比电容高达 $946 \mathrm{~F} \cdot \mathrm{g}^{-1}$, 能量 密度可达 $53 \mathrm{Wh} \bullet \mathrm{kg}^{-1}$, 功率密度为 $2.25 \mathrm{~kW} \cdot \mathrm{kg}^{-1}$, 且有 较好的循环稳定性.

综上所述, COM 材料种类众多, 在一定条件下热解 可以得到特定形态结构的碳材料. 通过合理选择前驱体 材料和模板以及合成工艺，可以实现控制最终产物组 成、孔隙结构和分布、比表面积以及导电性等性质，从 而更好的应用于高性能超级电容器. COM 材料衍生碳 材料在超级电容器电极材料领域有着良好的应用前景. 


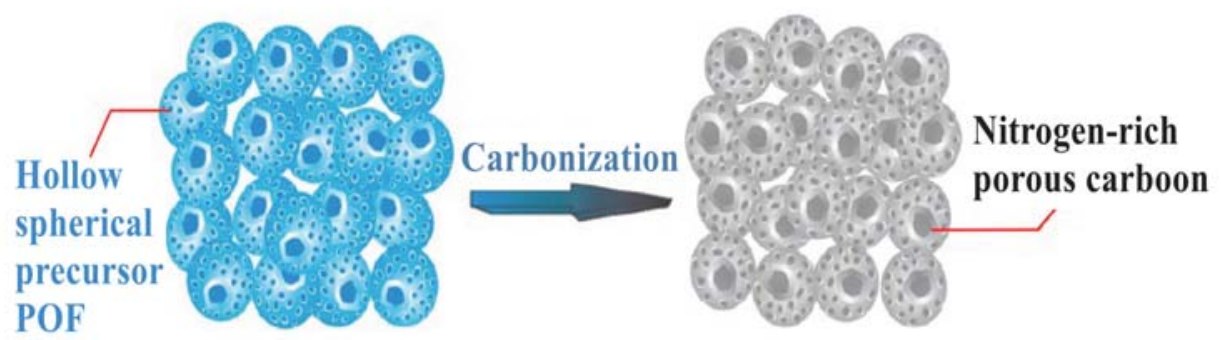

图 20 合成富氮多孔碳的示意图 ${ }^{[24]}$

Figure 20 Schematic illustration of the synthesis of nitrogen-rich porous carbon ${ }^{[124]}$

\section{6 总结与展望}

近年来，共价有机材料(Covalent organic materials: $\mathrm{COMs}$ ), 因高比表面积, 可裁剪孔结构, 和丰富的合成 平台, 得到了蓬勃发展. 在 $\mathrm{COM}$ 材料体系中, 共轭结构 赋予它优异的光电性质, 高的比表面积为静电电荷的分 离提供了充裕的界面, 固有的可裁剪孔结构允许离子的 传输, 加上高度有序的结构, 为载流子迁移提供了通道, 已经在半导体和能源转化与存储领域展示出诱人的潜 力. 伴随着多尺度模型化的高速发展, 可以定向设计调 控能带和光吸收性能, 来实现定制合成特定功能光电 $\mathrm{COM}$ 材料. 本综述围绕着 COM 材料, 总结 COM 材料 在半导体、能源转化 (光解水、太阳能电池、燃料电池 中的阴极氧化还原反应)、能源存储(锂电、锂硫、超级 电容器)中的应用, 并根据当前研究现状, 提出了设计 光电 $\mathrm{COM}$ 材料原理. 近年来, 除了利用 $\mathrm{COM}$ 材料本征 半导体性质制备光电器件外, 以 $\mathrm{COM}$ 材料为前驱体或 模板, 借助 COM 材料丰富便捷的化学和结构调控, 制 备高效多功能的 COM 衍生碳, 也得到了飞速的发展, 已经在氧还原和储能领域得到广泛的应用.

虽然光电 COM 材料被大量快速地报道了, 但其发 展仍处以萌芽期, 许多基础科学问题依然有待于解决:

第一, 控制合成特定能级的 COM 材料依然面临着 挑战. 在光电应用领域, 分子轨道能级: 最高分子占据 轨道和最低分子空轨道和能带起着关键作用. 理论上可 以很容易地定向设计甚至调控特定能级的 COM 材料, 然而最终实验合成出来的 COM 材料性质, 不一定能与 理论设计的结构完美吻合, 难于精确控制目标能级, 仍 需要进一步探索来攻克这一难题.

第二, 基于 $\mathrm{COM}$ 材料的光电器件加工依然面临很 大的挑战. 因 COM 材料结构是经过高度有序地组装起 来, 使得许多合成的 COM 材料具有很大的分子量, 导 致较差的溶解性, 甚至不溶解, 这给本征材料的结构表 征和器件加工成膜带来很大的挑战. 而通过引入亲水或 者相溶的基团, 又有可能影响本征导电性, 因此在 COM 材料不溶和难溶性质还有待于进一步研究突破.

第三, 合成具有良好本征导电性的 COM 材料有待
于取得更大突破. 当前报道中的 COM 材料, 大部分表 现出半导体特性, 而拓宽 COM 材料在新能源存储与转 化应用, 需要具有良好的本征导电性材料. 尽管基于 $\mathrm{COM}$ 材料为模板, 可以高温裂解出很多多功能、高活性 的电催化材料. 然而, 经高温裂解后, 其原始规则可控 的结构变得不可预测. 尽管可借助一些先进的原子尺度 表征, 但像母体一样清晰解析碳化后的结构, 依然面临 着巨大的挑战. 合成具有良好的本征导电性的 COM 材 料, 有利于借助可控的化学调控手段, 定向调控材料的 性能，更容易实现光电材料的 “私人定制”.

综上所述, COM 材料在光电领域已经展示出不可 低估的影响, 在半导体和新能源领域扮演着越来越重要 的作用，我们相信不久的将来会有越来越多的基于 $\mathrm{COM}$ 材料组装成的光电器件和新能源产品被研发出来.

\section{作者简介}

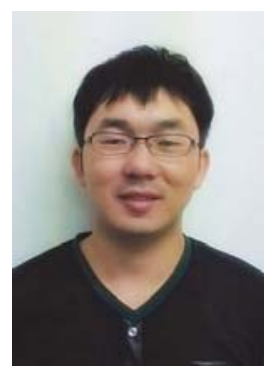

万刚, 北京化工大学有机无机复合材料国家重点实验室 2013 级研究生, 目前主要的研究方向为染料敏化太阳能电池 阳极改性研究以及新型结构钙钛矿太阳电池研究.

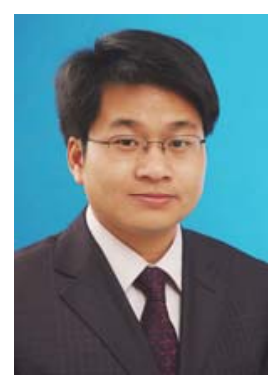

向中华, 北京化工大学教授. 2013 年在北京化工大学取得 博士学位, 之后在 Case Western Reserve University 大分子工程 
与科学系 Kent Hale Smith Prof. Liming Dai 实验室从事博士后 研究. 2014 年 8 月加入北京化工大学化工学院及有机无机复合 材料国家重点实验室，同时被聘为“分子能源材料研发中心” 负责人(PI). 现主要从事分子能源材料的基因设计与定向制备. 近五年内, 以第一作者在《Angew. Chem. Int. Ed.》、《Adv. Mater.》、《Energy Environ. Sci.》等 SCI 期刊发表论文 18 篇. 被 《Science》、《Nat. Chem.》等 SCI 他引超 600 次. 于 2013 年 获得教育部自然科学一等奖(排名第二).

\section{References}

[1] Zhou, H.-C.; Long, J. R.; Yaghi, O. M. Chem. Rev. 2012, 112, 673.

[2] Furukawa, H.; Cordova, K. E.; O'Keeffe, M.; Yaghi, O. M. Science 2013, 341, 974.

[3] Xiang, Z. H.; Cao, D. P.; Lan, J. H.; Wang, W. C.; Broom, D. P. Energy Environ. Sci. 2010, 3, 1469.

[4] Xiang, Z. H.; Hu, Z.; Cao, D. P.; Yang, W. T.; Lu, J. M.; Han, B. Y.; Wang, W. C. Angew. Chem., Int. Ed. 2011, 50, 491.

[5] Xiang, Z. H.; Peng, X.; Cheng, X.; Li, X. J.; Cao, D. P. J. Phys. Chem. C 2011, 115, 19864.

[6] He, Y.; Tan, Y.; Zhang, J. Acta Chim. Sinica 2014, 72, 1228. (何燕 萍, 谭衍曦, 张健, 化学学报, 2014, 72, 1228.)

[7] Liu, B.; Lian, Y.; Li, Z.; Chen, G. Acta Chim. Sinica 2014, 72, 942. (刘蓓, 廉源会, 李智, 陈光进, 化学学报, 2014, 72, 942.)

[8] Jia, J.; Wang, L.; Zhao, Q.; Sun, F.; Zhu, G. Acta Chim. Sinica 2013, 71,1492 . (贾江涛, 王蕾, 赵晴, 孙福兴, 朱广山, 化学学报, 2013, 71, 1492.)

[9] Zhu, W.-H.; Wang, Z.-M.; Gao, S. Inorg. Chem. 2007, 46, 1337.

[10] Li, W.; Gao, S.; Cheetham, A. K. Appl. Mater. 2014, 2, 123902.

[11] Xiang, Z. H.; Cao, D. P. J. Mater. Chem. A 2013, 1, 2691.

[12] Feng, X.; Ding, X.; Jiang, D. Chem. Soc. Rev. 2012, 41, 6010.

[13] Ding, S. Y.; Wang, W. Chem. Soc. Rev. 2013, 42, 548.

[14] Puthiaraj, P.; Pitchumani, K. Chem. Eur. J. 2014, $20,8761$.

[15] Zhao, Y.; Yao, K. X.; Teng, B.; Zhang, T.; Han, Y. Energy Environ. Sci. 2013, 6, 3684

[16] McKeown, N. B.; Budd, P. M. Macromolecules 2010, 43, 5163

[17] Ren, S.; Dawson, R.; Laybourn, A.; Jiang, J. X.; Khimyak, Y.; Adams, D. J.; Cooper, A. I. Polym. Chem. 2012, 3, 928.

[18] Xu, Y. H.; Jin, S. B.; Xu, H.; Nagai, A.; Jiang, D. L. Chem. Soc. Rev. 2013, 42, 8012 .

[19] Cooper, A. I. Adv. Mater. 2009, 21, 1291.

[20] Vilela, F.; Zhang, K.; Antonietti, M. Energy Environ. Sci. 2012, 5, 7819.

[21] Cheng, G.; Bonillo, B.; Sprick, R. S.; Adams, D. J.; Hasell, T.; Cooper, A. I. Adv. Funct. Mater. 2014, 24, 5219.

[22] Zhang, T.; Wang, H.; Ma, H.; Sun, F.; Cui, X.; Zhu, G. Acta Chim. Sinica 2013, 71, 1598. (张婷婷, 王海涛, 马和平, 孙福兴, 崔小 强, 朱广山, 化学学报, 2013, 71, 1598.)

[23] Jeon, H.-J.; Kim, D.-O.; Park, J.-S.; Kim, J.-S.; Kim, D.-W.; Jung, M.-S.; Shin, S.-W.; Lee, S.-W. Polymer-Korea 2011, 35, 66.

[24] Valderrama, C.; Gamisans, X.; Cortina, J. L.; Farran, A.; de Las Heras, F. X. J. Chem. Technol. Biotechnol. 2009, 84, 236.

[25] Yuan, D.; Lu, W.; Zhao, D.; Zhou, H.-C. Adv. Mater. 2011, 23, 3723.

[26] Lu, W. G.; Yuan, D. Q.; Sculley, J. L.; Zhao, D.; Krishna, R.; Zhou, H. C. J. Am. Chem. Soc. 2011, 133, 18126.

[27] Gao, X.; Lu, P.; Ma, Y. Chem. J. Chinese Univ. 2014, 35, 1795.

[28] Ben, T.; Qiu, S. CrystEngComm 2013, 15, 17.

[29] Ben, T.; Ren, H.; Ma, S.; Cao, D.; Lan, J.; Jing, X.; Wang, W.; Xu, J.; Deng, F.; Simmons, J. M.; Qiu, S.; Zhu, G. Angew. Chem., Int. Ed. 2009, 48, 9457.

[30] Wang, W.; Yan, Z.; Yuan, Y.; Sun, F.; Zhao, M.; Ren, H.; Zhu, G. Acta Chim. Sinica 2014, 72, 557. (王维, 间卓君, 元野, 孙福兴, 赵明, 任浩, 朱广山, 化学学报, 2014, 72, 557.)

[31] Xiang, Z. H.; Cao, D. P. Macromol. Rapid Commun. 2012, 33, 1184.

[32] Xiang, Z. H.; Wang, W. C.; Cao, D. P. Sci. China Chem. 2012, 42, 235. (向中华, 汪文川, 曹达鹏, 中国科学化学, 2012, 42, 235.)

[33] Xiang, Z. H.; Cao, D. P.; Wang, W. C.; Yang, W. T.; Han, B. Y.; Lu, J. M. J. Phys. Chem. C 2012, 116, 5974.

[34] Xiang, Z. H.; Zhou, X.; Zhou, C. H.; Zhong, S.; He, X.; Qin, C. P.; Cao, D. P. J. Mater. Chem. 2012, 22, 22663.

[35] Xiang, Z. H.; Xue, Y. H.; Cao, D. P.; Huang, L.; Chen, J. F.; Dai, L. M. Angew. Chem. Int. Ed. 2014, 53, 2433.

[36] Xiang, Z. H.; Cao, D. P.; Huang, L.; Shui, J. L.; Wang, M.; Dai, L.
M. Adv. Mater. 2014, 26, 3315.

[37] Dawson, R.; Cooper, A. I.; Adams, D. J. Prog. Polym. Sci. 2012, 37, 530.

[38] Zou, X.; Ren, H.; Zhu, G. Chem. Commun. 2013, 49, 3925.

[39] Bunz, U. H. F.; Seehafer, K.; Geyer, F. L.; Bender, M.; Braun, I.; Smarsly, E.; Freudenberg, J. Macromol. Rapid Commun. 2014, 35, 1466.

[40] Thomas, A. Angew. Chem., Int. Ed. 2010, 49, 8328.

[41] Zhu, G. S.; Ren, H. Porous Organic Frameworks: Design, Synthesis and Their Advanced Applications, Springer, 2014.

[42] Liu, X.-H.; Guan, C.-Z.; Wang, D.; Wan, L.-J. Adv. Mater. 2014, 26, 6912.

[43] Chang, Z.; Zhang, D. S.; Chen, Q.; Bu, X. H. Phys. Chem. Chem. Phys. 2013, 15, 5430.

[44] Dawson, R.; Cooper, A. I.; Adams, D. J. Polym. Int. 2013, 62, 345.

[45] Xu, H.; Chen, X.; Gao, J.; Lin, J.; Addicoat, M.; Irle, S.; Jiang, D. Chem. Commun. 2014, 50, 1292.

[46] Zhang, M.; Wang, X. Energy Environ. Sci. 2014, 7, 1902.

[47] Gu, C.; Huang, N.; Gao, J.; Xu, F.; Xu, Y. H.; Jiang, D. L. Angew. Chem., Int. Ed. 2014, 53, 4850.

[48] Altarawneh, S.; Nahar, L.; Arachchige, I. U.; Ala'a, O.; Hallal, K. M.; Kaafarani, B. R.; Rabbani, M. G.; Arvapally, R. K.; El-Kaderi, H. M. J. Mater. Chem. A 2015.

[49] Sang, N.; Zhan, C.; Cao, D. J. Mater. Chem. A 2015, 3, 92

[50] Chen, L.; Honsho, Y.; Seki, S.; Jiang, D. J. Am. Chem. Soc. 2010, 132,6742 .

[51] Jiang, J.-X.; Trewin, A.; Adams, D. J.; Cooper, A. I. Chem. Sci. 2011, 2, 1777.

[52] Xu, Y.; Chen, L.; Guo, Z.; Nagai, A.; Jiang, D. J. Am. Chem. Soc. 2011, 133, 17622.

[53] Guo, J.; Xu, Y. H.; Jin, S. B.; Chen, L.; Kaji, T.; Honsho, Y.; Addicoat, M. A.; Kim, J.; Saeki, A.; Ihee, H.; Seki, S.; Irle, S.; Hiramoto, M.; Gao, J.; Jiang, D. L. Nat. Commun. 2013, 4, 2736.

[54] Dogru, M.; Bein, T. Chem. Commun. 2014, 50, 5531.

[55] Guo, B.; Ben, T.; Bi, Z.; Veith, G. M.; Sun, X.-G.; Qiu, S.; Dai, S. Chem. Commun. 2013, 49, 4905.

[56] Choi, N.-S.; Han, J.-G.; Ha, S.-Y.; Park, I.; Back, C.-K. RSC Adv. 2015, 5, 2732.

[57] Su, Y.; Liu, Y.; Liu, P.; Wu, D.; Zhuang, X.; Zhang, F.; Feng, X. Angew. Chem., Int. Ed. 2015, 54, 1812

[58] Filer, A.; Choi, H.-J.; Seo, J.-M.; Baek, J.-B. Phys. Chem. Chem. Phys. 2014, 16, 11150.

[59] Lino, M. A.; Lino, A. A.; Mazzoni, M. S. C. Chem. Phys. Lett. 2007, 449, 171.

[60] Huang, L.; Xiang, Z. H.; Cheng, D. J.; Lan, J. H.; Wang, W. C.; Ben, T.; Cao, D. P. Nanotechnology 2012, 23, 395702.

[61] Xiang, Z. H.; Cao, D. P.; Dai, L. M. Polym. Chem. 2015, 6, 1896.

[62] Phillip, W. A.; O'Neill, B.; Rodwogin, M.; Hillmyer, M. A.; Cussler, E. L. ACS Appl. Mater. Interfaces 2010, 2, 847.

[63] Kimmins, S. D.; Cameron, N. R. Adv. Funct. Mater. 2011, 21, 211.

[64] Patwardhan, S.; Kocherzhenko, A. A.; Grozema, F. C.; Siebbeles, L. D. A. J. Phys. Chem. C 2011, 115, 11768.

[65] Mei, J.; Diao, Y.; Appleton, A. L.; Fang, L.; Bao, Z. J. Am. Chem. Soc. 2013, 135, 6724.

[66] Côté, A. P.; Benin, A. I.; Ockwig, N. W.; O'Keeffe, M.; Matzger, A. J.; Yaghi, O. M. Science 2005, 310, 1166.

[67] Lukose, B.; Kuc, A.; Frenzel, J.; Heine, T. Beilstein J. Nanotechnol. 2010, 1,60 .

[68] Lukose, B.; Kuc, A.; Heine, T. Chem. Eur. J. 2011, 17, 2388.

[69] Koo, B. T.; Dichtel, W. R.; Clancy, P. J. Mater. Chem. 2012, 22, 17460 .

[70] Medina, D. D.; Werner, V.; Auras, F.; Tautz, R.; Dogru, M.; Schuster, J.; Linke, S.; Doeblinger, M.; Feldmann, J.; Knochel, P.; Bein, T. ACS Nano 2014, 8, 4042.

[71] Colson, J. W.; Woll, A. R.; Mukherjee, A.; Levendorf, M. P.; Spitler, E. L.; Shields, V. B.; Spencer, M. G.; Park, J.; Dichtel, W. R. Science 2011, 332, 228.

[72] Xu, L.; Zhou, X.; Tian, W. Q.; Gao, T.; Zhang, Y. F.; Lei, S.; Liu, Z. F. Angew. Chem., Int. Ed. 2014, 53, 9564.

[73] Gunasinghe, R. N.; Reuven, D. G.; Suggs, K.; Wang, X.-Q. J. Phys. Chem. Lett. 2012, 3(20), 3048.

[74] Wan, S.; Guo, J.; Kim, J.; Ihee, H.; Jiang, D. Angew. Chem., Int. Ed. 2008, 120, 8958 .

[75] Wan, S.; Guo, J.; Kim, J.; Ihee, H.; Jiang, D. Angew. Chem., Int. Ed. 2009, 48, 5439

[76] Feng, X.; Chen, L.; Honsho, Y.; Saengsawang, O.; Liu, L.; Wang, L.; 
Saeki, A.; Irle, S.; Seki, S.; Dong, Y.; Jiang, D. Adv. Mater. 2012 , 24, 3026.

[77] Spitler, E. L.; Dichtel, W. R. Nat. Chem. 2010, 2(8), 672.

[78] Ding, X.; Guo, J.; Feng, X.; Honsho, Y.; Guo, J.; Seki, S.; Maitarad, P.; Saeki, A.; Nagase, S.; Jiang, D. Angew. Chem., Int. Ed. 2011, 50, 1289.

[79] Ding, X.; Chen, L.; Honsho, Y.; Feng, X.; Saenpawang, O.; Guo, J.; Saeki, A.; Seki, S.; Irle, S.; Nagase, S.; Parasuk, V.; Jiang, D. J. Am. Chem. Soc. 2011, 133, 14510.

[80] Jin, S. B; Ding, X. H; Feng, X.; Super, M.; Furukawa, K.; Takahashi, S.; Addicoat, M.; El-Khouly, M. E.; Nakamura, T.; Irle, S. Angew. Chem., Int. Ed. 2013, 52(7), 2017.

[81] Gandara, Y.; Asano, A.; Furukawa, H.; Sasaki, A.; Dey, S. K.; Liao, L.; Ambrogio, M. W.; Botros, Y. Y.; Duan, X. F.; Seki, S.; Stoddart, J. F.; Yaghi, O. M. Chem. Mater. 2011, 23(18), 4094

[82] Feng, X.; Liu, L.; Honsho, Y.; Saeki, A.; Seki, S.; Irle, S.; Dong, Y.; Nagai, A.; Jiang, D. Angew. Chem., Int. Ed. 2012, 51, 2618.

[83] Bertrand, G. H.; Michaelis, V. K.; Ong, T.-C.; Griffin, R. G.; Dincă, M. Proc. Natl. Acad. Sci. 2013, 110, 4923.

[84] Dogru, M.; Handloser, M.; Auras, F.; Kunz, T.; Medina, D.; Hartschuh, A.; Knochel, P.; Bein, T. Angew. Chem., Int. Ed. 2013, $52,2920$.

[85] Linsebigler, A. L.; Lu, G.; Yates Jr, J. T. Chem. Rev. 1995, 95, 735.

[86] Kudo, A.; Miseki, Y. Chem. Soc. Rev. 2009, 38, 253.

[87] Groenewolt, M.; Antonietti, M. Adv. Mater. 2005, 17, 1789.

[88] Wang, X.; Maeda, K.; Thomas, A.; Takanabe, K.; Xin, G.; Carlsson, J. M.; Domen, K.; Antonietti, M. Nat. Mater. 2008, 8, 76.

[89] Wang, X.; Maeda, K.; Chen, X.; Takanabe, K.; Domen, K.; Hou, Y.; Fu, X.; Antonietti, M. J. Am. Chem. Soc. 2009, 131, 1680.

[90] Li, Q.; Yue, B.; Iwai, H.; Kako, T.; Ye, J. J. Phys. Chem. C 2010, 114,4100 .

[91] Stegbauer, L.; Schwinghammer, K.; Lotsch, B. V. Chem. Sci. 2014, $5,2789$.

[92] Habas, S. E.; Platt, H. A.; van Hest, M. F.; Ginley, D. S. Chem. Rev. 2010, $110,6571$.

[93] Hoppe, H.; Sariciftci, N. S. J. Mater. Res. 2004, 19, 1924.

[94] Joshi, D.; Shivanna, R.; Narayan, K. S. J. Mod. Optic. 2014, 61, 1703.

[95] Chang, J. A.; Rhee, J. H.; Im, S. H.; Lee, Y. H.; Kim, H.-J.; Seok, S. I.; Nazeeruddin, M. K.; Gratzel, M. Nano Lett. 2010, 10, 2609.

[96] Heo, J. H.; Im, S. H.; Noh, J. H.; Mandal, T. N.; Lim, C.-S.; Chang, J. A.; Lee, Y. H.; Kim, H.-J.; Sarkar, A.; Nazeeruddin, M. K.; Graetzel, M.; Seok, S. I. Nat. Photonics 2013, 7, 487.

[97] O’Regan,B.; Gratzel, M. Nature 1991,353,737.

[98] Chen, L.; Furukawa, K.; Gao, J.; Nagai, A.; Nakamura, T.; Dong, Y.; Jiang, D. J. Am. Chem. Soc. 2014, 136, 9806.

[99] Gasteiger, H. A.; Kocha, S. S.; Sompalli, B.; Wagner, F. T. Appl. Catal. B-Environ. 2005, 56, 9.

[100] Feng, Y. J.; Alonso-Vante, N. Phys. Status Solidi B 2008, 245, 1792.

[101] Zhao, H.; Jin, Z.; Su, H.; Jing, X.; Sun, F.; Zhu, G. Chem. Commun. 2011, 47, 6389.

[102] Pachfule, P.; Dhavale, V. M.; Kandambeth, S.; Kurungot, S.; Banerjee, R. Chem. Eur. J. 2013, 19, 974.
[103] Wu, Z. S.; Chen, L.; Liu, J. Z.; Parvez, K.; Liang, H. W.; Shu, J.; Sachdev, H.; Graf, R.; Feng, X. L.; Mullen, K. Adv. Mater. 2014, 26, 1450 .

[104] Zhuang, X.; Zhang, F.; Wu, D.; Forler, N.; Liang, H.; Wagner, M.; Gehrig, D.; Hansen, M. R.; Laquai, F.; Feng, X. Angew. Chem., Int. Ed. 2013, 52, 9668.

[105] Zhang, Y.; Zhuang, X.; Su, Y.; Zhang, F.; Feng, X. J. Mater. Chem. A 2014, 21(2), 7742 .

[106] Song, Z.; Zhou, H. Energy Environ. Sci. 2013, 6, 2280.

[107] Xu, F.; Chen, X.; Tang, Z.; Wu, D.; Fu, R.; Jiang, D. Chem. Commun. 2014, 50, 4788.

[108] Huang, Y.; Wu, D.; Wang, J.; Han, S.; Lv, L.; Zhang, F.; Feng, X. Small 2014, 10, 2226.

[109] Kwon, M.-S.; Choi, A.; Park, Y.; Cheon, J. Y.; Kang, H.; Jo, Y. N.; Kim, Y.-J.; Hong, S. Y.; Joo, S. H.; Yang, C.; Lee, K. T. Sci. Rep. 2014, 4, 7404.

[110] Poizot, P.; Laruelle, S.; Grugeon, S.; Dupont, L.; Tarascon, J. Nature 2000, 407, 496.

[111] Bruce, P. G.; Scrosati, B.; Tarascon, J.-M. Angew. Chem., Int. Ed. 2008, 47, 2930

[112] Xiao, L.; Cao, Y.; Xiao, J.; Schwenzer, B.; Engelhard, M. H.; Saraf, L. V.; Nie, Z.; Exarhos, G. J.; Liu, J. Adv. Mater. 2012, 24, 1176.

[113] Tarascon, J. M.; Armand, M. Nature 2001, 414, 359.

[114] Goodenough, J. B.; Kim, Y. Chem. Mater. 2010, 22, 587.

[115] Liao, H.; Ding, H.; Li, B.; Ai, X.; Wang, C. J. Mater. Chem. A 2014, 2,8854 .

[116] Winter, M.; Brodd, R. J. Chem. Rev. 2004, 104, 4245.

[117] Feng, X.; Liang, Y.; Zhi, L.; Thomas, A.; Wu, D.; Lieberwirth, I.; Kolb, U.; Müllen, K. Adv. Funct. Mater. 2009, 19, 2125.

[118] Liang, Y.; Feng, X.; Zhi, L.; Kolb, U.; Müllen, K. Chem. Commun. 2009, 809.

[119] Bao, Q.; Bao, S.; Li, C. M.; Qi, X.; Pan, C.; Zang, J.; Lu, Z.; Li, Y.; Tang, D. Y.; Zhang, S. J. Phys. Chem. C 2008, 112, 3612.

[120] Béguin, F.; Szostak, K.; Lota, G.; Frackowiak, E. Adv. Mater. 2005, $17,2380$.

[121] Raymundo-Piñero, E.; Leroux, F.; Béguin, F. Adv. Mater. 2006, 18 , 1877.

[122] Xiang, Z. H.; Wang, D.; Xue, Y. H.; Dai, L. M.; Chen, J. F.; Cao, D. P. Sci. Rep. 2015, 5, 8307.

[123] Li, Y.; Roy, S.; Ben, T.; Xua, S.; Qiu, S. Phys. Chem. Chem. Phys. 2014, 16, 12909.

[124] Liu, X.; Zhou, L.; Zhao, Y.; Bian, L.; Feng, X.; Pu, Q. ACS Appl. Mater. Interfaces 2013, 5, 10280.

[125] Zhuang, X.; Zhang, F.; Wu, D.; Feng, X. Adv. Mater. 2014, 26, 3081 .

[126] Yang, X.; Zhuang, X.; Huang, Y.; Jiang, J.; Tian, H.; Wu, D.; Zhang, F.; Mai, Y.; Feng, X. Polym. Chem. 2015, 6, 1088.

[127] Kou, Y.; Xu, Y.; Guo, Z.; Jiang, D. Angew. Chem., Int. Ed. 2011, 50, 8753.

[128] Yamada, H.; Nakamura, H.; Nakahara, F.; Moriguchi, I.; Kudo, T. J. Phys. Chem. C 2007, 111, 227. 